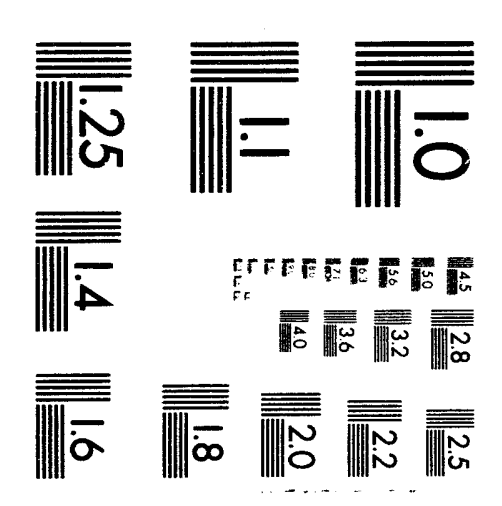



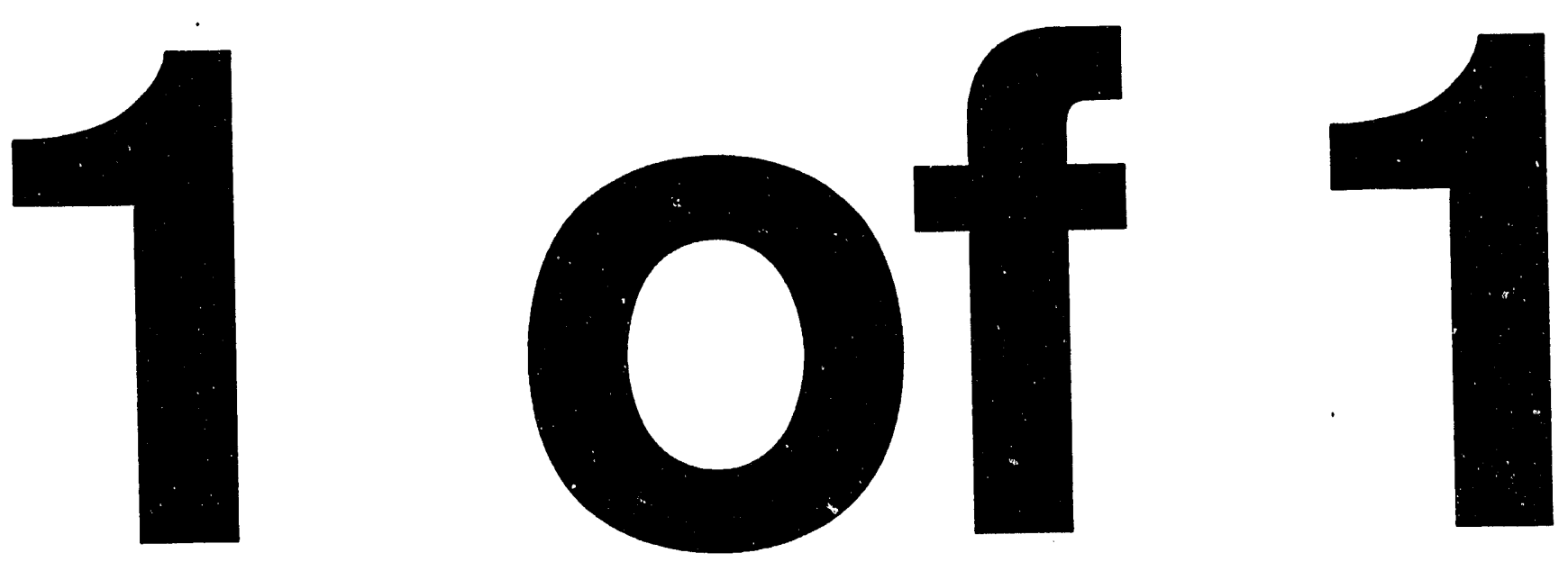
ORNL/TM-12495

Dist. Category UC-20a, d, f

Fusion Energy Division

\title{
PLASMA SURFACE CLEANING IN A MICROWAVE PLASMA SOURCE
}
C. C. Tsai
H. H. Haselton
W. D. Nelson
D. E. Schechter

Oak Ridge National Laboratory
L. M. Thompson
A. L. Glover
V. B. Campbell
J. M. Googin
Oak Ridge Y-12 Plant

Date Published: March 1994

\author{
Prepared by \\ OAK RIDGE NATIONAL LABORATORY \\ Oak Ridge, Tennessee 37831 \\ managed by \\ MARTIN MARIETTA ENERGY SYSTEMS, INC. \\ for the \\ U.S. DEPARTMENT OF ENERGY \\ under contract DE-AC05-84OR21400
}




\section{CONTENTS}

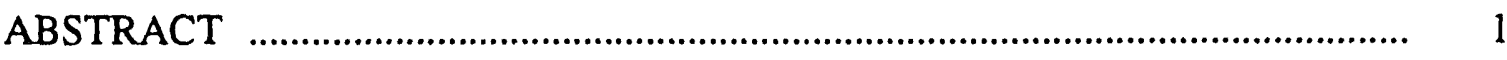

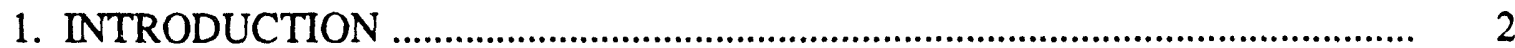

2. EXPERIMENTAL ARRANGEMENT …………………...................................

3. PLASMA PROPERTIES ………............................................................. 5

4. PLASMA CLEANING ……………………………...............................

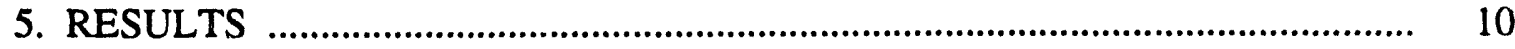

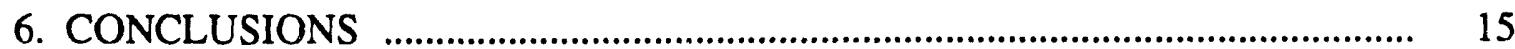

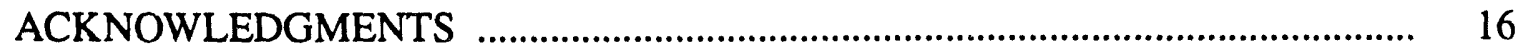

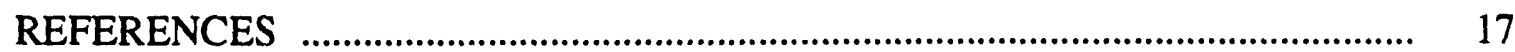




\begin{abstract}
A microwave electron cyclotron resonance(ECR) plasma source has been operated to produce reactive plasmas of oxygen and its mixture with argon. Aluminum samples $(0.95 \mathrm{~cm}$ by $1.9 \mathrm{~cm})$ were coated with thin films ( $\leq 20 \mu \mathrm{m}$ in thickness) of Shell Vitrea oil and cleaned by using such reactive plasmas. The plasma cleaning was done in discharge conditions of microwave power up to $1300 \mathrm{~W}$, radio frequency power up to $200 \mathrm{~W}$, biased potential up to $400 \mathrm{~V}$, gas pressures up to $5 \mathrm{mtorr}$, and operating time up to $35 \mathrm{~min}$. The surface texture of the postcleaned samples has been examined visually. Mass loss of the samples after plasma cleaning was measured to estimate cleaning rates. Measured clean rates of low-pressure (0.5-mtorr) argon/oxygen plasmas were as high as $2.7 \mu \mathrm{m} / \mathrm{min}$. X-ray photoelectron spectroscopy (XPS) was used to determine cleanliness of the sample surfaces after plasma cleaning. The Y.PS study on polished samples confirmed the effectiveness of plasma cleaning in achieving atomic level of surface cleanliness. In this technical memorandum plasma properties, cleaning phenomena, and significant results are reported and discussed.
\end{abstract}




\section{Introduction}

Plasma surface cleaning has been widely used to achieve clean surfaces in fusion energy research, in high-energy accelerators, and in materials processing. ${ }^{1-3}$ This cleaning method utilizes radical species generated in reactive gas discharges to remove surface contaminants. The energetic radical species in these discharges consist of photons, electrons, ions, and reactive neutral species. Physically, these energetic particles impinge on surfaces to cause sputtering, thermal evaporation, or photodecomposition. Chemically, the surface heating caused by these energetic particles greatly enhances chemical reactions. These impinging particles are generally very hot; for example, $1 \mathrm{eV}$ of energy is equivalent to a temperature of the order of $11,600 \mathrm{~K}$. Thus, the energetic plasma particles have higher rates of chemical reactions with surface contaminants than those of thermal reactive gas particles.

It is well known that reactive oxygen plasmas are very effective for removing organic contaminants from surfaces. The dominant reactive species in oxygen plasmashot electrons, energetic ions, atomic radicals, ozone, and ultravio!et (UV) photonsactively clean organic contaminants by physical sputtering, thermal evaporation, chemical reaction, or photodecomposition. By controlling gas pressure, applied power, and other discharge parameters, we may use such reactive plasma particles with suitable energy and flux to perform gentle, damage-free cleaning on contaminated surfaces. Given their capability for producing useful reactive plasmas, microwave electron cyclotron resonance (ECR) plasma source ${ }^{4}$ have been chosen for development of alternative cleaning techniques to replace conventional solvent cleaning. To this end, an experimental test stand has been prepared and equipped with an existing ECR plasma source 5 that was originally developed at Oak Ridge National Laboratory (ORNL). Initially, the experiment is intended to demonstrate plasma cleaning on small test samples with hydrocarbon contaminants. Eventually, we will develop cleaning techniques for finished workpieces. The cleaning techniques so developed should provide uniform surface cleaning over workpieces with complex shapes, eliminate physical distortion, and minimize production of secondary wastes.

At ORNL, plasma generators in duoPIGatron ion sources have been developed for neutral beam injectors used in fusion plasma heating. $6-8$ Equipped with a hot cathode and a magnetic multicusp confinement, these plasma geneiators are capable of producing uniform hydrogen plasmas over broad ion accelerators (diameter up to $30 \mathrm{~cm}$ ) and forming hydrogen ion beams of $100 \mathrm{~A}$ at $50 \mathrm{keV}$. The corresponding neutral beam injectors have been operated to inject multimegawatt beams of energetic hydrogen or 
deuterium atoms for heating fusion plasmas. For etching application in manufacturing microelectronics, we have successfully replaced the hot cathode in the plasma generator by a microwave launcher that creates energetic electrons for plasma generation. This new plasma generator is called a microwave ECR multicusp plasma source. 5

The ECR plasma source (Fig. 1) consists of a microwave launcher, a source magnet, a multicusp plasma chamber, and an ion accelerator. The source magnet surrounding the microwave launcher can be excited to provide an $875-\mathrm{G}$ s field for establishing an ECR zone in which electrons gain energy from the applied $2.45-\mathrm{GHz}$ microwave electric field. In the middle of the source magnet, a commercial MDL glass/Kovar pressure window between the standard S-band waveguide and the launcher provides a vacuum-tight seal. This arrangement of high field launch of microwave energy can create dense plasmas well above $10^{11}$ per cubic centimeter. On the outside walls of the multicusp plasma chamber (30 cm in diameter and $20 \mathrm{~cm}$ in height), 20 columns of samarium cobalt permanent magnets are equally spaced with alternating polarity for forming a multipleline cusp configuration. This magnetic configuration confines both the energetic ECR electrons and the cold plasma electrons and thus enhances the ionization and the ECR discharges. Depending upon the gas pressures or gas density, this plasma source can produce plasmas with different spatial profiles, as shown in Fig. 2. The plasma profiles are measured by an electrical probe scanned in a radial plane at the downstream end of the discharge chamber. The plasma source has been operated for producing uniform plasmas of oxygen and argon with useful densities over large areas of 300 to $400 \mathrm{~cm}^{2}$ for etching applications. 5,9

In the following sections, we describe the experimental test stand, including diagnostics, and the operating characteristics of the plasma source. The significant results for test samples cleaned in reactive plasmas of oxygen, argon, or their mixture are then reported. Finally, the mechanisms for cleaning organic contaminants and forming oxides on sample surfaces are discussed.

\section{Experimental Arrangement}

Employing available hardware and equipment, we have set up an experimental facility in the Plasma Physics Laboratory located in Room 259 of Building 9201-2 at the Oak Ridge Y-12 plant. Figure 3 shows a test stand with an ECR microwave plasma source, a vacuum chamber, and an associated vacuum pump. Other supporting equipment in the experimental facility are control consoles, a vacuum system, electrical and electronics equipment, and a water-cooling system. On the control consoles, the electrical 
and electronics equipment are used to control the vacuum system, to conduct experiments, and to provide diagnostics. A microwave $(2.45-\mathrm{GHz})$ supply is used to provide microwave energy for creating plasmas in the ECR plasma source on the test stand. A rauilo frequency $(\mathrm{rf}, 13.56-\mathrm{MHz})$ supply is used to provide an rf biasing potential to the sample holder in the ECR plasma source. The low-voltage dc supply on the control console is an alternative biasing supply for the sample holder. The sample holder in Fig. 3, which is similar to the ion accelerator in Fig. 1, is electrically insulated from the grounded plasma chamber. Two low-voltage supplies are used separately to excite the source coil on the top plate of the plasma chamber and the enhancing magnet, which surrounds the sample holder and is mounted on the vacuum chamber.

As shown in Fig. 3, the vacuum chamber is mounted on the frame of the test stand. Both are grounded. The ECR plasma source is set on the top flange of the vacuum chamber. On the top of the test stand, a source lifting device is used to raise the source chamber up and away from the vacuum chamber. This lifting arrangement is for the convenience of changing test samples, which are often placed on the center of the sample holder. Bolted on the bottom flange of the vacuum chamber is the rf feedthrough on which the sample holder is fastened. The vacuum chamber has many ports for diagnostics and pumping. The vacuum chamber is evacuated by a turbomolecular pump through a 90-deg elbow vacuum pipe on the side port.

The vacuum pump system consists of the turbomolecular pump, vacuum pipes, gate valves, vacuum gauges, and a mechanical fore pump. The pumping speed of the turbomolecular pump is about $400 \mathrm{~L} / \mathrm{s}$ for air. The gas pressure in the plasma source is measured by a capacitance manometer (MKS Baratron Type 170M-6C). An ionization gauge at the entrance of the turbomolecular pump is used to measure pressure in the vacuum chamber. The achievable base pressure is below $1 \times 10^{-6}$ torr. A butterfly throttle valve on the turbomolecular pump controls the pumping speed. The working gas is fed through a needle valve into the top flange of the plasma chamber and is distributed uniformly. The needle valve regulates the gas flow rate, which is measured by a flowmeter. Both the needle valve and the throttle valve are used to adjust the gas pressure in the source. To handle reactive gases such as oxygen and its mixtures, we use a Fumblin fluid for the mechanical fore (or roughing) pump. This inert fluid is a perfluorinated polyether that has high oxidation resistance and high flash point for handling high-oxygen conditions in plasma processing.

A residual gas analyzer (RGA), UTI $100 \mathrm{C}$, installed at a side port of the vacuum chamber downstream of the plasma source, is used to monitor gaseous species in the vacuum chamber. A typical background mass spectrum (I) under vacuum without gas 
feed is showr in Fig. 4. The spectrum (I) reveals that major background gas particles are hydrogen (mass 2 peak), hydroxide (mass 17 peak), water (mass 18 peak), carbon monoxide (mass 28 peak), and carbon dioxide (mass 44 peak). For mass 28 peak, the possibility of having appreciable nitrogen has been ruled out by the absence of mass 14 peak. With a pure oxygen feed, the signals of oxygen atoms (mass 16 peak) and molecules (mass 32 peak) appear with a substantial increment in signal amplitudes on the spectrum (II in Fig. 4). During the pulsed low-pressure oxygen discharges among major components of RGA mass scan, the mass 28 peak for carbon monoxide $(\mathrm{CO})$ of ten changes drastically, as shown in Fig. 5. (Dynamic changes of other mass peaks during discharges will be studied by using a computer data acquisition system). In the early phase of plasma cleaning discharges the measured mass 28 peak during pulsed discharges is usually higher than that in between. But at the end of discharge cleaning, the mass 28 peak usually decreases to a lower value during the pulsed discharge. Thus the waveforms of the mass 28 peak can be used to indicate the status of plasma cleaning. Figure 6 shows a curve of the maximum value of mass 28 peak as functions of the accumulated plasma cleaning time. It indicates high cleaning rates of the oxygen plasma discharges.

\section{Plasma Properties}

Under normal operations, the operating pressure is kept constant by feeding gas continuously. The exciting current of the source coil (or magnei and the microwave power are pulsed on for a duration variable up to $5 \mathrm{~s}$ every 10 to $20 \mathrm{~s}$. A matching network (3-stub tuner) in the waveguide between the microwave supply and the plasma source is then adjusted for minimal reflected power and kept at that setting during each experimental sequence. Plasma density and spatial uniformity at the downstream end of the plasma chamber (about $20 \mathrm{~cm}$ away from the microwave launcher) are measured by a scanning electrical probe .

Such plasma sources have been operated with argon, hydrogen, and oxygen. Qualitatively, the general effects of operating parameters on plasma properties are similar for different working gases. Typical argon plasmas in low-pressure ( $\leq 1-\mathrm{mtorr})$ discharges have electron densities of $\sim 1 \times 10^{11} \mathrm{~cm}^{-3}$, electron temperatures of 2 to $5 \mathrm{eV}$, and a production efficiency near $200 \mathrm{~W} / \mathrm{A}$ ( $200 \mathrm{eV} / \mathrm{ion})$. The plasma properties for different discharge conditions are published elsewhere. ${ }^{5,9}$ In general, the plasma profiles are axially symmetric. For high-pressure discharges with relatively short mean free paths compared to the length of the plasma chamber, the energetic ECR electrons tend to dissipate their energies via various collision processes with the gas particles. Such 
microwave ECR discharges produce dense plasmas in a region near the ECR zone at the exit end of microwave launcher and in the upstream end of the plasma chamber. Diffusing along the expanding magnetic field lines toward the downstream probe plane, such plasmas tend to have axially peaked profiles. At low-pressure discharges, mean free paths of electrons are often longer than the length of the plasma chamber. Before creating ions from gas particles by ionization collisions, the energetic ECR electrons near the axis can be intercepted and removed by the grounded sample holder or substrate. However, the off-axis energetic electrons can be reflected by the cusp field near the chamber walls. These reflected electrons have higher probability to produce ions through reflex discharges between the microwave window and the chamber wall. The reflex discharges produce plasmas in such a hollow and conic shell region. Diffusing along the magnetic field lines to the downstream probe plane, such plasmas tend to have hollow profiles. The curves in Fig. 2 reveal such gas-pressure effects on plasma uniformity. 5,9

Configured similarly to Fig. 1, the microwave plasma source shown in Fig. 3 has plasma properties similar to those briefly described above. With new arrangements of the sample holder and the enhancing magnet, the plasma source in Fig. 3 has additional flexibility in controlling plasma distributions. We observed the following significant effects on plasma density distributions as functions of the biased potentials of the sample holder and the exciting currents of the enhancing magnet.

The biased potential of the sample holder $(-14 \mathrm{~cm}$ in diameter) can significantly affect confinement and ionization of energetic electrons and, thus, plasma density and uniformity. Such biased potential effects on plasma distribution for low-pressure oxygen discharges are shown in Figs, 7-9. Their common discharge parameters are a source pressure of $0.5 \mathrm{mtorr}$, a source coil current of $480 \mathrm{~A}$, and an applied microwave power of $400 \mathrm{~W}$. In such low pressures of $0.5 \mathrm{mtorr}$, the mean free path of electrons colliding with oxygen molecules at room temperatures is about $60 \mathrm{~cm}$ (three times plasma chamber length). For the data points in Fig. $7(a)-(e)$, probe ion currents $\mathrm{I}_{\mathrm{p}}$ and $\mathrm{I}_{\mathrm{p}}$ are denoted for grounded and floated bare sample holders, respectively; and $40 \mathrm{~A}, 0 \mathrm{~A}$, and $-40 \mathrm{~A}$ are the values for the enhancing magnet current $I_{e m}$. The positive (negative) value of the current $\mathrm{I}_{\mathrm{em}}$ is denoted, respectively, for the same (opposite) polarity with respect to the source magnetic field. In such low-pressure discharges, the floating potential of the sample holder is charged negatively by the energetic electrons and varies between -4 and $-30 \mathrm{~V}$. The corresponding kinetic energies of such electrons varies up to $30 \mathrm{eV}$. The floating potential tends to increase with increasing of the applied microwave power. The negatively floated sample holder is capable of reflecting some of approaching energetic electrons, which could lose part of their axial kinetic energy through electron-gas 
collisions. These electrons move back and forth between the ECR zone and the floated sample holder and initiate a reflex microwave discharge. With additional confinement of the source magnetic fields, such reflex discharges can maximize ionization efficiency of energetic electrons and increase plasma density. Thus, in the region near the chamber axis, higher probe ion current was measured in such reflex discharges for the floated sample holder than that was measured in diode discharges for the grounded sample holder. In these discharges, the density and uniformity of plasmas outside the sample holder should be independent of the biasing potential of the sample holder. These two features are clearly shown by the data points in Figs. $7(a)$ and $(b)$. Furthermore, the data points with hollow plasma profiles are for diode discharges with the grounded sample holder, and those with axially peaked plasma profiles are for reflex discharges with the negatively floated sample holder. In Fig. 7(a) and (b), the plasma profiles for the reflex discharges change sharply at radii near $7 \mathrm{~cm}$, which is the radius of the sample holder. This feature reveals the important biasing effect of the sample holder and the field effect of the enhancing magnet. However, the data points in Fig. $7(c)$ show another field effect on enhancing plasma uniformity. The corresponding polarity of the source and enhancing magnets is opposite to each other and forms a cusp field in a transverse plane above the sample holder. The energetic electrons from the ECR zone move along the cusp field lines towards and are reflected back by multicusp magnetic fields near the plasma chamber walls. A microwave reflex discharge is established in the region surrounded by these cusp magnetic fields. Only the plasma particles so created diffuse or drift toward the sample holder. Consequently, the measured plasma profiles are relatively uniform and almost independent of the sample holder potential, as shown in Fig. 7(c). The data points in Figs. 7(a)-(c) have been redrawn in Fig. $7(d)$ and $(e)$ for the grounded and the floated sample holder, respectively. The only discharge parameter changed in each figure is the enhanced magnetic field. For diode discharges with the grounded sample holder, Fig. $7(d)$ reveals that the enhancing magnet with the opposite polarity (as denoted by $-I_{e m}$ ) will form a cusp field, improve electron confinement, enhance ionization, increase plasma density, and improve plasma uniformity. For reflex discharges with the floated sample holder, Fig. 7(e) reveals that the enhancing magnet with the same polarity (as denoted by $+\mathrm{I}_{\mathrm{em}}$ ) and increased axial magnetic field strength will improve confinement of energetic electrons, intensify the discharges near the chamber axis, and achieve higher ion currents as measured.

For data in Fig. 8(a)-(c), the probe currents $\mathrm{I}_{\mathrm{p}}$ and $\mathrm{I}_{\mathrm{p}^{\prime}}$ are denoted, respectively, for the grounded $(0 \mathrm{~V})$ and the positively biased $(+25 \mathrm{~V})$ bare sample holder; and 0 and $40 \mathrm{~A}$ are the values for the enhancing magnet current $\mathrm{I}_{\mathrm{em}}$. Usually the positively biased sample 
holder increases electron loss from volume plasmas and reduces their ionization efficiency. Thus, the plasmas of these discharges have lower density and are characterized by the similar hollow profile, as compared to diode discharges with the grounded sample holder, as shown in Fig. 8(a) and (b). Similarly, the enhancing magnetic field (having the same polarity as the source magnetic field) constrains the energetic electrons axially and increases their loss to the positively biased sample holder and further lowers plasma density in the discharges. This feature is clearly shown by the plasma profiles of replotted Fig. 8(c).

For data in Fig. $9(a)-(c)$, the probe currents $I_{p}$ and $I_{p}$ are denoted respectively for the grounded $(0 \mathrm{~V})$ and the negatively biased $(-50 \mathrm{~V})$ sample holder; and 0 and $40 \mathrm{~A}$ are the values for the enhancing magnet current $\mathrm{I}_{\mathrm{em}}$. With the negatively biased sample holder, the reflex discharges behave similarly to those with a negatively floated sample holder [Fig. 7(e)]. As shown in Fig. 9(a) and (b), the highly peaked plasma profiles are measured for reflex discharges with the negatively biased sample holder, while the hollow plasma profiles are for diode discharges with the grounded sample holders. The plasma density for those peaked profiles changes sharply at radii near $7 \mathrm{~cm}$, which is the radius of the sample holder. This feature further reveals the important effect of the negatively biased sample holder on the low-pressure reflex discharges. Redrawn plasma profiles in Fig. 9(c) reveal that the applied enhancing magnetic fields can improve electron confinement, plasma production, and plasma density in reflex discharges with the negatively biased sample holder.

As the pressure is increased, the energetic electrons move along the divergent source magnetic field lines, dissipate their axial energies through collisions with gas particles, and produce plasmas in the upstream region of the discharge chamber. Thus, the discharges at slightly higher pressures have a higher plasma density, as shown by the data points in Fig. 10(a) These data points were taken for diode discharges with the grounded sample holder and without the enhancing magnetic fields. When the source gas pressure is increased further, fewer energetic electrons and more plasma ions can arrive at the downstream region of the discharge chamber; thus, the floating potential of the sample holder will change from negative to positive values. The resulting increase in electron loss and decrease in ion generation near the sample holder may lead to lower probe ion current at higher pressure discharges, as shown in Figs $10(b)$ and $(c)$. When the gas pressure is increased to 3-mtorr from 0.6-mtorr, the mean free path of electrons is shortened to $\sim 10 \mathrm{~cm}$ from $\sim 50 \mathrm{~cm}$, respectively. Thus, the energetic electrons dissipate their energies through gas collisions for plasma production in the upper half of the discharge chamber. The increased plasma density in such discharges can cause 
impedance mismatch and have a large reflected power. This will reduce microwave power dissipation in the discharges, reduce electric field in the ECR zone, and produce fewer energetic electrons than at lower pressure discharges. This will further reduce energetic electrons arriving at the region near the biased sample holder and decrease plasma production there. For higher-pressure discharges the measured probe ion currents could be lower than those for lower-pressure discharges, as shown in Figs. $10(b)$ and $(c)$. Even after the 3-stub tuner is reoptimized with an impedance match, the higher-pressure discharges could still have lower measured probe ion currents than the lower-pressure discharges. This feature is shown in Fig. 10(d). In such high-pressure discharges, a floated sample holder can be charged dominantly by positive ions and have a positive floating potential. Similarly, the plasma potential (or probe floating potential) is also positive. In such discharges, the electron confinement of magnetic multicusp fields is relatively insignificant, because the ion loss from volume plasma to sample holder and chamber walls controls the plasma density. Consequently, a small fraction of plasma ions arrives at the downstream end of the plasma chamber. Thus, the measured plasma density right above the sample holder for such high-pressure discharges can be substantially lower than that measured for low-pressure discharges.

\section{Plasma Cleaning}

Plasma cleaning experiments have been conducted with reactive plasmas of oxygen and its mixture with argon to remove oil films on small test samples $(0.95 \mathrm{~cm}$ by 1.91 $\mathrm{cm}$ ) made of aluminum 6061. The samples are prepared by cleaning the top surfaces with alcohol spray, using an air jet to dry them, and then coating the top surfaces with a thin film of Shell Vitrea oil. The mass of the oil film on each test sample is determined by weighing the sample before and after the coating with oil film. With a measured oil density of $865 \mathrm{mg} / \mathrm{cm}^{3}$, typical thickness of uniform films is about 6 to $19 \mu \mathrm{m}$ for a 1 - to 3-mg oil coating. The prepared test sample was then placed on the center of the sample holder, which can be covered with a Pyrex plate as shown in Fig. 11(a)-(c). Figure 11(a) shows a test sample that can be placed in the center hole $(2.54 \mathrm{~cm}$ in diameter $)$ of the Pyrex glass plate. Test samples can be arranged in different configurations, as shown in Fig. $11(b)$ and $(c)$, to simulate samples with concave and convex surfaces.

After the vacuum chamber is evacuated, the base pressure of vacuum chamber can be below $2 \times 10^{-6}$ torr. The RGA can be turned on to confirm that there is no vacuum leakage. For each cleaning experiment, the cooling water for the test stand is turned on first. The desired gas pressure in the plasma chamber is adjusted by regulating gas flow 
rate and pumping speed. The RGA is then used to measure gas purity and record various mass peaks on a chart record. (A computer data acquisition system will be used in the coming year). If needed, the enhancing magnet can be powered with a constant exciting current. Subsequently, the magnet, radio frequency (rf), and microwave power supplies are armed for pulsed operations. The plasma cleaning facility is ready for operation.

Usually microwave ECR discharges are initiated and sustained by applying a pulsed exciting current to the source coil and a pulsed power to the microwave launcher simultaneously. The source coil current is variable up to $500 \mathrm{~A}$, while the microwave power is variable up to $1500 \mathrm{~W}$. The typical pulse-on time is 1 to $5 \mathrm{~s}$ at a duty factor of 10 to $50 \%$, respectively. The pulsed rf power can be changed to bias the sample holder with different negative potentials up to $-200 \mathrm{~V}$. To ensure operator safety and adhere to Occupational Safety and Health Administration (OSHA) regulations, the microwave and rf leakage outside the fence of the safety interlock cage enclosing the test stand is measured and checked before pursuing routine plasma cleaning experiments.

During these experiments, the current density of the plasma is monitored with the electrical probe. Other operating parameters-such as gas pressure, gas flow rate, microwave forward and reflected powers, magnet currents, biasing potential of the sample holder, and operating time (or accumulated plasma exposure time)-are also recorded. During the discharge cleaning experiments, the gas pressure readings tend to change slightly from \pm 10 to $\pm 20 \%$ due to changes of gas feed rate, plasma pumping, gas dissociation, and contaminant vaporization. The amplitude of carbon monoxide (CO) of the RGA mass spectrum is monitored and recorded on a chart. After cleaning, the weight loss of each sample is measured, and surface texture changes are examined under an optical microscope. Subsequently, test sample surfaces are studied using the XPS analysis.

\section{Results}

Tables 1-3 list forty-six test samples (92-1 to 92-46) that were studied in 1992. All these samples except $92-46$ were subjected to low-pressure ( $\leq 1-$ mtorr source pressure) plasma cleaning. Oil mass is the oil coated on the sample surface. Samples with zero oil mass were bare samples without oil coating and used as collectors to collect condensable particles produced in the plasma. Mass loss is the mass removed by plasma cleaning. Residual mass is the mass of residual oil, equivalent to that the oil mass minus the mass loss. Other operating parameters of the plasma cleaning are also listed in the table. Surface feature is used to highlight the appearance of sample surfaces after plasma 
cleaning. It reveals that samples tend to have etched and sputtered surface damage whenever negative dc biased potentials on the sample holder exceeding $75 \mathrm{~V}$. However, samples with rf biasing can be plasma cleaned and free of etched damage even when the biased potentials exceeded $150 \mathrm{~V}$. The mass loss and operating time can be used to estimate the cleaning rate as listed in Table 4. The operating time of sample 92-31 in Table 2 indicated that fast cleaning rates can be achieved by using argon/oxygen plasmas and $150-\mathrm{V}$ rf biased potential.

The reactive plasma discharges of oxygen or oxygen/argon are effective in cleaning thin oil films. With a negatively biased sample holder, plasma ions are accelerated to high energies. Such energetic ion bombardment on sample surfaces enhances chemical reactions between hydrocarbon molecules and plasma particles, leads to decomposition and vaporization of the oil film, and produces a volatile gas effluent. Thus, plasma cleaning rate is a sensitive function of plasma density and ion energy, which can be affected by the biased potential to the test samples. Figure 12 shows that the average cleaning rate on these test samples increases with the if biased potential. The maximum cleaning rate of $2.7 \mathrm{~mm} / \mathrm{min}$ occurs at a rf biased potential of about $-165 \mathrm{~V}$. This implies that the energetic ions play the prime role in cleaning up oil films. The kinetic energy of impinging ions can greatly affect the sputtering yields of surface layers. For example, the impinging ions can enhance physical sputtering on sample surfaces whenever ion energies are above $50 \mathrm{eV}$. Alternatively, we can use plasmas of an oxygen/argon gas mixture to influence sputtering on the sample surfaces. In such plasmas, the energetic argon ions actively and effectively break carbon-oxygen bonds in organic layers formed on the sample surfaces. We noticed that the reactive plasma of oxygen/argon mixtures can shorten the plasma cleaning time by two to three times, as listed in Table 2. We also noticed that higher average cleaning rates were achieved for cases with shorter accumulated plasma cleaning time. This feature is shown in Fig. 13.

With oxygen plasma cleaning, the dominant species of gaseous effluent arriving at the RGA are $\mathrm{H}_{2}, \mathrm{O}, \mathrm{OH}, \mathrm{H}_{2} \mathrm{O}, \mathrm{CO}, \mathrm{O}_{2}$, and $\mathrm{CO}_{2}$. During the discharge, oxygen molecules are partially ionized, excited, and dissociated. These oxygen particles are either held in the discharge volume or consumed by chemical reactions with hydrocarbon molecules. The waveforms of spectra $\mathrm{O}_{2}$ tend to be lowered during the discharge duration, as shown in Fig. 14. Under intense bombardment of oxygen plasma particles, hydrocarbon molecules in the oil film on sample surfaces are very active in chemical reactions with the plasma particles and produce volatile gas products. One of the dominant products is CO. The waveform B in Fig. 5 shows that the mass 28 peak of CO changes greatly during the pulsed discharge. Such changes are very sensitive to the 
surface conditions of the sample. Figure 15 records the amplitude changes of mass 28 peak of $\mathrm{CO}$ during a sequence of pulsed plasma cleaning. At the beginning of the plasma cleaning, the amplitude of the mass 28 increases rapidly to a maximum, then decreases slowly. At the end of the plasma cleaning, the amplitude varies insignificantly and slightly decreases during the pulsed discharges. For this type of plasma cleaning, the waveform of mass 28 (or $\mathrm{CO}$ ) peak closely correlates to the cleanliness of the sample surfaces. It is ideal to use $\mathrm{CO}$ waveforms for recording the history of plasma cleaning and for indicating the end point of the cleaning.

Moreover, when an oil film on the sample surface is being exposed to oxygen plasma, its aromatic groups are readily evaporated and diffused into the plasma volume. These hydrocarbon molecules in both the plasma volume and the oil film undergo chemical reactions with oxygen plasma particles and produce voiatile gases such as $\mathrm{CO}$ and $\mathrm{CO}_{2}$. Subsequent formation of carbonyl groups on the film surfaces slows down the production of hydrocarbon vapors and reduces its chemical reactions with plasma particles. Similar to those observed in etching polymers in pure oxygen plasmas, ${ }^{10}$ this phenomenon may explain the measured cleaning rates as a decreasing function of operating time, as shown in Fig. 13. In argon/oxygen plasmas, the bombardment of energetic argon ions on the oil film surfaces may break carbon to carbon or carbon to oxygen bonds and enhance oxygen-carbon reactions there. The synergetic effect of physical sputtering and chemical reactions may explain the observed higher cleaning rates of reactive plasmas of oxygen/argon.

For simulating concave or convex geometry of real workpieces, some samples were tilted and placed in the center hole of the Pyrex plate on the sample holder [as shown in Fig. $11(b)$ and $(c)$ and cleaned by the reactive plasmas. Based on the mass loss and cleaning rate listed in Tables 3 and 4, the paired samples (92-37 and 92-38, 92-39 and 9240, 92-42 and 92-43, and 92-44 and 92-45) can be cleaned at a rate similar to that for the flat samples. While the drooping of oil film due to plasma heating and gravity tends to leave carbon spots on the surfaces at the bottom end of the tilted samples, most of the sample surfaces were relatively clean.

The cleanliness of sample surfaces after plasma cleaning can be examined qualitatively by using an optical microscope. Table 4 describes the surface features of test samples as noted by visual inspection. Quantitatively, the cleanliness of surfaces can be analyzed by an XPS and can be determined by the value of C/Al in the top $40 \AA$ of the surface layers. Here, C/Al is the ratio of carbon to aluminum measured by the XPS analysis. The XPS analysis can be done in the following two modes. The broad spot mode $(3 \times 10 \mathrm{~mm})$ measures the average chemical composition in the surface layers of 
these samples. The small spot mode $(0.8-\mathrm{mm}$ diameter $)$ measures a typical chemical composition. If the value of $\mathrm{C} / \mathrm{Al}$ for a plasma-cleaned sample is larger than that for a bare sample, or if their difference $\Delta(\mathrm{C} / \mathrm{Al})$ is a positive value, the sample surface is not cleaned. For example, sample 92-1 was cleaned mainly by electrons and still had smeared oil residues on its surfaces after plasma cleaning. The XPS analysis cannot detect the signal of aluminum. The value of $\Delta(\mathrm{C} / \mathrm{Al})$ for this unclean sample exceeds 500,000 , as shown in Table 4. Collectors 92-24, 92-26, and 92-30 were set on the Pyrex plate on a dc biased sample holder and were floated at plasma floating potentials during plasma cleaning. These collectors tend to collect condensable oil vapors and oxide particles created by the plasma cleaning. With low kinetic energies, any plasma ions impinged on collector surfaces cannot sputter away surface particles. Thus, these collectors have large values of $\Delta(\mathrm{C} / \mathrm{Al})$ and have dirty surfaces with golden color, as listed in Table 4. However, collectors 92-34 and 92-36 were relatively clean. These collectors were set on the Pyrex plate on the rf biased sample holder and had small or negative $\Delta(\mathrm{C} / \mathrm{Al})$. With rf biasing, the plasma ions can gain sufficient energies to sputter away dirty particles on collector surfaces. Having negative values of $\Delta(\mathrm{C} / \mathrm{Al})$, as shown in Fig. 16, the majority of test samples with rf biasing were cleaned by such reactive plasmas of argon/oxygen mixtures.

In 1993, a refined experimental study on cleanliness of sample surfaces has been done by using the XPS analysis on polished test samples before and after plasma cleaning. In Table 5 each bare sample has been prepared to achieve a mirror surface $(\sim 0.5 \mu \mathrm{m}$ in flatness) by polishing and ultrasonic cleaning. After being coated with thin films ( $\sim 6 \mu \mathrm{m}$ thick) of Shell Vitrea oil, the samples were then plasma-cleaned. The XPS survey analyzed the surface composition of the top $40 \AA$ surface layers in a spot size of $0.8 \mathrm{~mm}$. With a sample size of 9.5 by $19.1 \mathrm{~mm}$, the $0.8-\mathrm{mm}$ spot survey revealed only the typical surface composition. The cleanliness of each test sample and relevant plasma cleaning parameters are given in Table 5. If the value of $\mathrm{C} / \mathrm{Al}$ ratio was below the average value of 1.15 from control samples, the test sample was considered to be clean. Similarly, the oxide layer has been thinned down by plasmas, if the value of $\mathrm{O} / \mathrm{Al}$ is below 3.34. Significant results of the recent study on 11 samples in Table 5, are summarized below:

1. All samples were clean except samples $92-73$ and 92-74. Similarly, the oxide layer of all cleaned samples was thinner, except in the two dirty samples that were grown thicker in oxygen plasmas.

2. The first six samples were cleaned by oxygen plasmas at a source pressure of $\sim 0.5$ mtorr with a negative dc biasing potential ranging from 0 to $100 \mathrm{~V}$. The sample 
surface was damaged with etch marks under high biased potential; for example, sample 92-51 was biased negatively at $100 \mathrm{~V}$.

3. The last five samples were cleaned by oxygen plasmas at a source pressure of 5 mtorr. Such oxygen plasma were not effective for cleaning oil-contaminated samples $92-73$ and 92-74 with dc biasing. However, the plasmas are very effective for cleaning the last three samples with of biasing. This feature associated with the sample biasing implies that plasma ions are dominant in the plasma surface cleaning. We speculate that the insulated oil film on the sample surfaces may reduce ion energies gained under dc biasing.

The alloy composition of bare test samples is $\mathrm{Al} 98 \%, \mathrm{Mg} 0.8$ to $1.2 \%, \mathrm{Si} 0.4$ to $0.8 \%, \mathrm{Cr} 0.2 \%$, and $\mathrm{Cu} 0.3 \%$, as listed in Table 6. This table also lists the composition of analyzed bare samples as "Control" in the rows 92-50-CON, 92-72-CON, and 92-100CON and their mean in the row "Control Mean." The average composition of these control samples is $\mathrm{Al} 17.2 \%, \mathrm{O} 57.5 \%, \mathrm{C} 19.8 \%, \mathrm{Mg} \mathrm{0 \% ,} \mathrm{Ca} \mathrm{0.7 \% ,} \mathrm{Si} \mathrm{0.9 \% ,} \mathrm{Cu} \mathrm{0 \% ,} \mathrm{Ag}$ $0 \%, \mathrm{P} 3.2 \%$, and $\mathrm{Cr} 0 \%$. The average surface composition of plasma-cleaned samples 92-50, 92-72, and 92-100 (or Sample Mean) listed is $\mathrm{Al} 22.1 \%, \mathrm{O} 48.6 \%, \mathrm{C} 25.7 \%, \mathrm{Mg}$

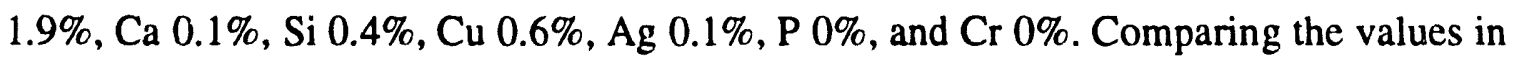
the rows "Sample Mean, "Control Mean" and "Bulk Alloy," we can highlight the following significant points.

1. The surface of these control samples was covered with a thin oxide layer with carbon impurities.

2. These polished bare samples were contaminated with materials of polishing powders. In fact, the XPS survey did not detect the elements of $\mathrm{Mg}, \mathrm{Cu}$, and $\mathrm{Cr}$ in the bulk alloy, but did detect $\mathrm{Ca}, \mathrm{Si}$, and $\mathrm{P}$, which are in polishing powders but not in constituents of the bulk alloy.

3. The surfaces of the plasma-cleaned samples are cleaner than those of the control bare samples. This statement is supported by the higher aluminum atomic concentration and lower oxygen concentration for the plasma-cleaned samples. The values of the $\mathrm{C} / \mathrm{Al}$ ratio for 92-50 and 92-72 are smaller than those values for their control bare samples. These values confirmed better cleanliness on surfaces of the plasma-cleaned samples.

4. The great decrease of $\mathrm{Ca}, \mathrm{Si}$, and $\mathrm{P}$ on post-plasma-cleaned samples indicates that the polished powder contaminates on surfaces were cleaned up by oxygen plasmas. 
The presence of magnesium on these plasma-cleaned samples indicates that the surface layer has been partially removed.

\section{Conclusions}

Preliminary results reveal that reactive plasma cleaning works well for test samples coated with Shell Vitrea oil films with thicknesses approaching $20 \mu \mathrm{m}$. The experimental facility has been operated to demonstrate its capability of creating reactive plasmas of oxygen or oxygen/argon and performing surface cleaning. In low-pressure (ranging from 0.3- to 5-mtorr) discharges, reactive plasmas have been created and powered by microwave and $\mathrm{rf}$ energies. Various plasma distributions, either axially peak or hollow profiles, can be controlled by both the enhancing magnet and the biased sample holder. Small flat aluminum samples coated with thin films $(<20 \mu \mathrm{m})$ of Shell Vitrea oil have been plasma cleaned and their surface cleanliness has been analyzed by the XPS. The significant results are summarized below.

1. The dominant cleaning particles in oxygen and argon/oxygen plasmas are energetic ions. This is consistent with that higher negatively biased potential to the sample holder, shorter the cleanup time, and higher the clean rates.

2. Argon/oxygen plasmas have cleaning rates 2 to 3 times higher than those of oxygen plasmas when other plasma cleaning parameters are kept constant.

3. The cleaning rates of oxygen $/ 30 \%$-argon plasmas can be as high as $2.7 \mu \mathrm{m} / \mathrm{min}$.

4. For thick oil films $(-20 \mu \mathrm{m})$, only samples with $\mathrm{rf}$ biasing can be effectively cleaned in high-pressure ( $\sim 5-$ mtorr oxygen) plasmas. The oxygen plasmas cannot clean a dc biased sample.

5. Samples with rf biasing can be cleaned without etch damage at biased potentials up to $200 \mathrm{~V}$, but samples with $-75 \mathrm{~V}$ dc biasing tend to have etch damage on sample surfaces.

6. For both flat samples, tilted samples for simulating a concave or convex geometry of finished workpieces can be cleaned at similar rates.

7. The XPS analysis for measuring relative concentration of aluminum, carbon, and oxygen on sample surfaces confirmed that the post-plasma-cleaned samples can be cleaner than the control bare samples. 


\section{Acknowledgments}

The authors would like to thank their colleagues who helped with this project, particularly L. A. Berry and W. L. Stirling for their valuable discussion, B. E. Argo and G. C. Barber for their technical support in keeping electrical and electronic equipment functional at the facility, and to J. E. Simpkins for his advice on the use of a residual gas analyzer. 


\section{References}

1. H. F. Dylla, "Glow discharge techniques for conditioning high-vacuum systems," $J$. Vac. Sci. Technol. A 6 (3), 1276-1287 (1988).

2. J. W. Coburn, "Surface processing with partially ionized plasmas," IEEE Trans. on Plasma Science 19 (6), 1048-1062 (1991).

3. W. Shmayda and A. Antoniazzi, "Tritium decontamination - plasma driven decontamination technique," Canadian Fusion Fuels Technology Project Journal 8 (3), ISSN 0847-9437. (May 1992).

4. J. Asniussen, "Electron cyclotron resonance microwave discharges for etching and thin film deposition," in Handbook of Plasma Processing Technology, S. M. Rossnagel, J. J. Cuomo, and W. D. Westwood (Noyes Publication, 1990), Chap. 11.

5. C. C. Tsai et al., "Potential applications of an electron cyclotron resonance multicusp plasma source,"J. Vac. Sci. Technol. A 8 (3), 2900-2903 (1990).

6. W. L. Stirling, C. C. Tsai, and P. M. Ryan, " $15 \mathrm{~cm}$ duoPIGation ion source," Rev. Sci. Instrum. 48, 533 (1977).

7. C. C. Tsai et al., "DuoPIGatron ion source for PLT injectors," in Proc. 7th Int. Symp. on Engineering Problems of Fusion Research (IEEE, New York, 1977), pp. 278-283.

8. H. H. Haselton, "Neutral-beam injectur research and development in the United States," 8th Int. Conf. on Plasma Physics and Controlled Nuclear Fusion Research, Brussels, Belgium, July 1-10, 1980.

9. C. C. Tsai, "Potential applications of a new microwave electron cyclotron resonance multicusp plasma source," Nucl. Instr. and Methods in Physics Research B 56/57, 1166-1170 (1991).

10. G. N. Taylor and T. M. Wolf, "Oxygen plasma removal of thin polymer films,"J. Polymer Eng. Sci. 20, 1087 (1980). 


\begin{tabular}{|c|c|c|c|c|c|c|c|c|c|c|c|}
\hline & & & & & & & & & & & \\
\hline & & & & Table 1. Oxyg & en plasma cleani & ing on alu & iminum samples a & coated with oil f & film & & \\
\hline & & & & & & & & & & & \\
\hline \multirow[t]{2}{*}{ Sample ID } & Date & Oil mass & Mass loss & Residual mass & Biased potentialF & Remarks & Current density & Operating time & Source pressure & Surface feature & Mictowave power \\
\hline & & mo (mg) & $\mathrm{m}^{\prime}(\mathrm{mg})$ & $\Delta \mathrm{m}(\mathrm{mg})$ & Vsh (V) & & $\mathrm{J}\left(\mathrm{mA} / \mathrm{cm}^{\wedge} 2\right)$ & $t(s)$ & psc (mlorr) & & $P \mu w(W)$ \\
\hline $92-1$ & $3-26 / 3-30$ & 1.2 & 0.6 & 0.6 & 50 & $\mathrm{dc}$ & 1 & 1550 & 0.25 & Smeared residues & 540 \\
\hline $92-2$ & $3-30 / 3-31$ & 1.1 & 1.1 & 0 & -50 & $\mathrm{dc}$ & 8 & 1612 & 0.5 & Clean & 540 \\
\hline $92-3$ & 3-31/3-31 & 1.2 & 0.9 & 0.3 & -50 & $\mathrm{dc}$ & 7.4 & 1638 & 0.8 & Unclean & 540 \\
\hline $92-4$ & $3-31 / 4-2$ & 1.1 & 1.2 & -0.1 & -60 & dc & 6.5 & 1637 & 0.8 & Unclean & 980 \\
\hline $92-5$ & $4-2 / 4-3$ & 1 & 0.8 & 0.2 & -60 & dc & 6.5 & 1615 & 0.6 & Unclean & 980 \\
\hline $92-6$ & $4-2 / 4-3$ & 0 & 0 & 0 & -60 & dc & 6.5 & 1615 & 0.6 & Clean & \\
\hline $92-7$ & 4-3/4-3 & 1 & 1.2 & -0.2 & -60 & $\mathrm{dc}$ & 5.5 & 2000 & 0.25 & Unclean & 540 \\
\hline $92-8$ & 4-3/4-3 & 0 & 0 & 0 & -60 & $\mathrm{dc}$ & 5.5 & 2000 & $0 . \overline{25}$ & Clean & 540 \\
\hline $92-9$ & $4-3 / 4-6$ & 0.8 & 1 & -0.2 & -100 & $\mathrm{dc}$ & 7.7 & 2000 & 0.5 & Etched & 540 \\
\hline $92-10$ & $4-3 / 4-9$ & 0 & -0.2 & 0.2 & -75 & $\mathrm{dc}$ & & 8060 & 0.5 & Etched & 540 \\
\hline $92-11$ & 4-6/4-8 & 1 & 1.2 & -0.2 & -75 & dc & 6.6 & 2000 & 0.5 & Etched & 540 \\
\hline $92-12$ & $4-8 / 4-9$ & 1.3 & 1.1 & 0.2 & -56 & $\mathrm{dc}$ & 6.2 & 2000 & 0.47 & Etched & \\
\hline $92-13$ & 4-9/4-10 & 1.1 & 0.8 & 0.3 & -60 & $\mathrm{dc}$ & 6.3 & 2000 & 0.5 & Etched & 540 \\
\hline $92-14$ & 4-10/4-14 & 1.1 & 0.9 & 0.2 & -25 & $\mathrm{dc}$ & 7.5 & 2000 & 0.47 & Clean & 540 \\
\hline $92-15$ & 4-10/4-14 & 0 & 0.2 & -0.2 & & Floating & 0 & 2000 & 0.5 & Clean & 540 \\
\hline $92-16$ & $4-14 / 4-16$ & 0.8 & 0.7 & 0.1 & -25 & If & 7.2 & 2000 & 0.47 & Clean & 540 \\
\hline $92-17$ & $4-14 / 4-16$ & 0 & 0 & 0 & & Floating & 0 & 11500 & 0.5 & Golden Color & $540-1300$ \\
\hline $92-18$ & 4-16/420 & 1.6 & 1.4 & 0.2 & -50 & Floating & 7.4 & 2000 & 0.47 & Tiny oil drops & 540 \\
\hline \multirow[t]{5}{*}{$92-19$} & 4-20/4-21 & 1.5 & 1.3 & 0.2 & -50 & If & 7.4 & 2000 & 0.47 & Clean & 935 \\
\hline & & & & & & & & & & & $\ldots$ \\
\hline & & & & & & & & & & & $\ldots \ldots$ \\
\hline & & & & & & & & & & $\ldots \ldots$ & $\ldots \ldots \ldots$ \\
\hline & & & & & & & & & & $\ldots \ldots$ & $\ldots \ldots$ \\
\hline \multicolumn{12}{|l|}{ Note: } \\
\hline \multicolumn{12}{|c|}{ 1. Vsh, biased potential of the sample holder with dc or if biasing. } \\
\hline \multicolumn{4}{|c|}{ 2. Source coil current (ism) was $480 \mathrm{~A}$. } & & & & & & & & \\
\hline \multicolumn{7}{|c|}{ 3. Enhancing magnet current was zero for samples $92-1$ to $92-8$, and $+40 \mathrm{~A}$ for others. } & & & & & \\
\hline
\end{tabular}




\begin{tabular}{|c|c|c|c|c|c|c|c|c|c|c|c|}
\hline & & & & & & & & & & \multirow{2}{*}{$+\ldots$} & \\
\hline & & & & & \multicolumn{5}{|c|}{ Table 2. Plasma cleaning on aluminum samples coated with oil film } & & $\ldots$ \\
\hline \multirow{2}{*}{ Sample ID } & \multirow{2}{*}{ Date } & Oil mass & \multicolumn{2}{|c|}{ Mass loss Residual mass } & Biased potential & Remarks & \multicolumn{3}{|c|}{ Current density Operating time Source pressure } & \multirow{2}{*}{ Surface feature } & Mictowave power \\
\hline & & mo $(\mathrm{mg})$ & $\mathbf{m}^{\prime}(\mathrm{mg})$ & $\Delta m(m g)$ & Vsh (V) & & $\mathrm{Ji}\left(\mathrm{mA} / \mathrm{cm}^{\wedge} 2\right)$ & $t(s)$ & psc (mtorr) & & $\mathrm{P} \mu w(W)$ \\
\hline $92-17$ & $4-14 / 4-24$ & 0 & 0 & 0 & & Floating. $\mathrm{O} 2$ & 0 & 11500 & 0.5 & Golden Color & 540 to $13(x)$ \\
\hline $92-20$ & $4-21 / 4-22$ & 1 & 1 & 0 & 45 & rf. $\mathrm{O} 2$ & 10 & 2015 & 0.52 & Clean & $13(6)$ \\
\hline $92-21$ & $4-22 / 4-23$ & 1 & 1.2 & -0.2 & -40 & $\mathrm{rf}, \mathrm{O} 2$ & 10 & 2015 & 0.35 & clean & 1317 \\
\hline $92-22$ & $4-23 / 4-24$ & 1.1 & -3.9 & 5 & -25 & $\mathrm{rf}, \mathrm{O} 2$ & 5.5 & 1395 & 0.8 & clean & 1310 \\
\hline $92-23$ & $4-27 / 4-29$ & 0 & 0 & 0 & -150 & If, $\mathrm{O} 2$ & 8.6 & 2100 & 0.37 & Light Golden Colot & 1267 \\
\hline $92-24$ & $4-27 / 4-29$ & 0 & 0 & 0 & & Floating, $\mathrm{O} 2$ & 8.6 & 2100 & 0.37 & Golden Color & 1267 \\
\hline 92.25 & $4-29 / 5-1$ & 1.4 & 2.4 & -1 & -200 & dc, $\mathrm{O} 2$ & 7 & 1536 & 0.3 & Etched & 1340 \\
\hline $92-26$ & $4-29 / 5-1$ & 0 & 0.4 & -0.4 & & Floating, $\mathrm{O} 2$ & 7 & 1536 & 0.3 & Golden Color & 1340 \\
\hline $92-27$ & $5-1 / 5-4$ & 0 & 1.2 & -1.2 & -400 & dc, $\mathrm{Ar}$ & 5.6 & 1500 & 0.29 & Etched & 970 \\
\hline $92-28$ & $5-1 / 5-4$ & 0 & 1.2 & -1.2 & -400 & dc. $\mathrm{Ar}$ & 5.6 & 1500 & 0.29 & Clean & 970 \\
\hline $92-29$ & $5-5 / 5-7$ & 1.8 & 1.9 & -0.1 & -110 & $\mathrm{If}, \mathrm{O} 2+27 \% \mathrm{Ar}$ & 3 & 1550 & 0.3 & Clean & 980 \\
\hline $92-30$ & $5-5 / 5-7$ & 0 & 0.2 & -0.2 & & $\mathrm{~F} 1 ., \mathrm{O} 2+27 \% \mathrm{Ar}$ & 3 & 1550 & 0.3 & Golden Color & 980 \\
\hline $92-31$ & $5-7 / 5-8$ & 1.7 & 1.8 & -0.1 & -150 & If, $\mathrm{O} 2+27 \% \mathrm{Ar}$ & 4 & 646 & $0 . \overline{32}$ & Clean & 980 \\
\hline $92-32$ & $5-7 / 5-8$ & 0 & 0.1 & -0.1 & & $\mathrm{Fl} ., \mathrm{O} 2+27 \% \mathrm{Ar}$ & 4 & 646 & 0.32 & Clean & 980 \\
\hline & & & & & & & & & & & $\ldots$ \\
\hline & & & & & & & & & & & \\
\hline & & & & & & & & & & & \\
\hline NOTES: & & & & & & & & & & & \\
\hline 1. Vsh, bia & sed potentia & the sam & ple holder & hich is float & ting, rf, or dc bias & sing as remarked & & & & & \\
\hline 2. Test san & nples were c & aned in $a$ & plasma of & xygen, argon, & or their mixture & & & & & & \\
\hline 3. Source c & coil current & m) was 48 & $80 \mathrm{~A}$. & & & & & & & & \\
\hline 5. Enhanci & ing magnet c & ment (lem) & was +40 & & & & & & & & \\
\hline
\end{tabular}




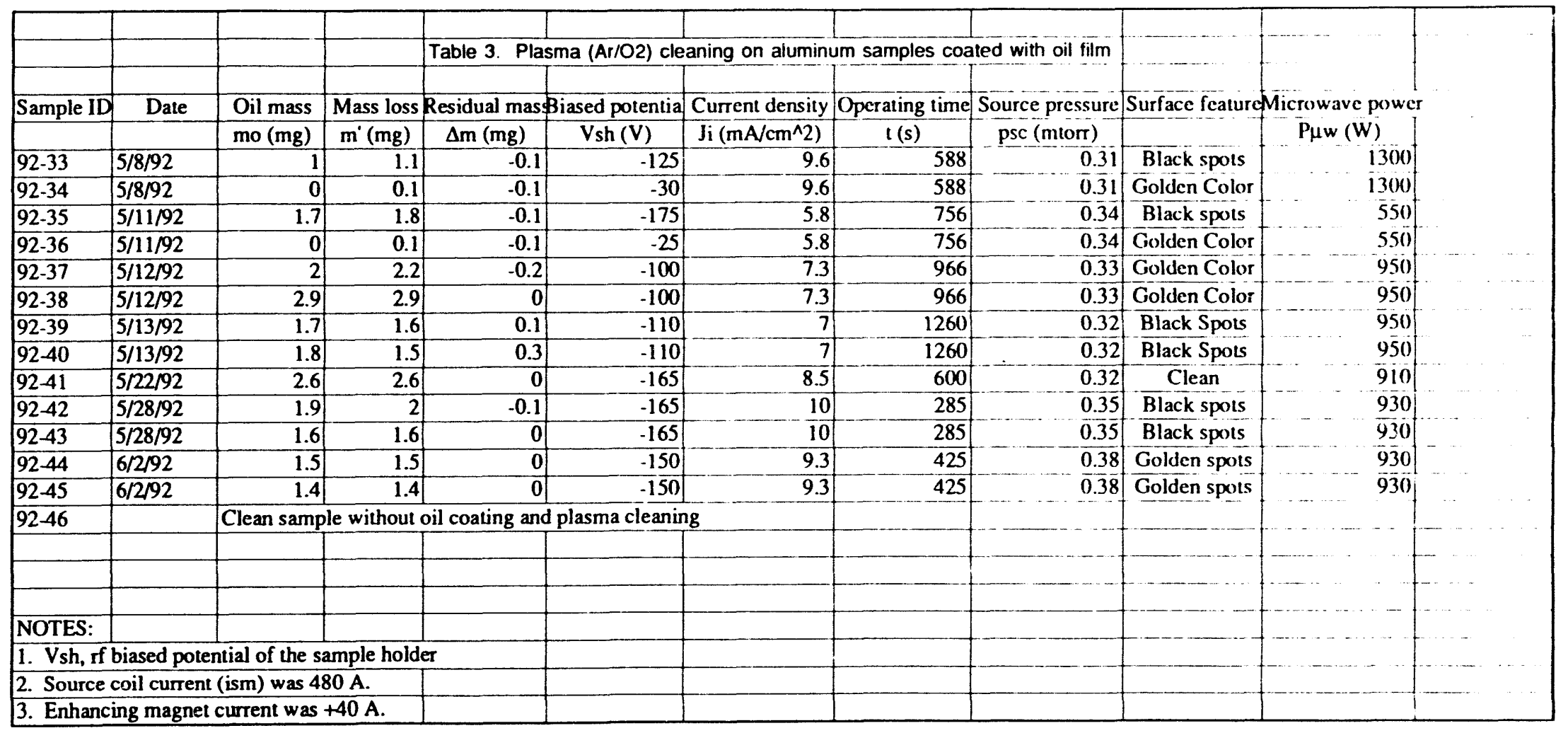




\begin{tabular}{|c|c|c|c|c|c|c|c|c|c|}
\hline & & & & & & & & & \\
\hline & & & Table 4. An & alyzed results of te & st samples listed i & Tables 1-3 & & & \\
\hline \multirow{2}{*}{ Sample ID } & Oilmess & Mass loss & Film cleaned & Operating time & Cleaning rate & Cleanliness & Microwave powen & Surface feature & Biased potential \\
\hline & mo (mg) & $m^{\prime}(m g)$ & $\Delta \mathrm{l}(\mu \mathrm{m})$ & $t$ (min.) & $(\mu \mathrm{m} / \mathrm{min})$ & $\Delta(\mathrm{C} / \mathrm{Al})$ & P $\mu w(W)$ & & $V_{s h}(V)$ \\
\hline & & & & & & 53710835 & 540 & Smeared residues & $+50 \mathrm{dc}$ \\
\hline$\frac{92-1}{92-2}$ & $\begin{array}{l}1.20 \\
1.10\end{array}$ & $\frac{0.60}{1.10}$ & $\begin{array}{c}3.84 \\
7.04\end{array}$ & $\begin{array}{l}25.8 \\
26.9\end{array}$ & 0.15 & $\begin{array}{r}53798.35 \\
-0.58\end{array}$ & $\begin{array}{l}340 \\
540\end{array}$ & Clean & $-50 \mathrm{dc}$ \\
\hline $92-3$ & 1.20 & 0.90 & 5.76 & 27.3 & 0.21 & 0.31 & 540 & Unclean & $-50 \mathrm{dc}$ \\
\hline $92-4$ & 1.10 & 1.20 & 7.68 & 27.3 & 0.28 & 1.06 & 980 & Unctean & $-60 \overline{d c}$ \\
\hline 92.5 & 1.00 & 0.80 & 5.12 & 26.9 & 0.19 & 1.17 & 980 & Unclean & $-60 \bar{d} d c$ \\
\hline $92-6$ & 0.00 & 0.00 & 0.00 & 26.9 & 0.00 & -0.56 & 980 & Clean & $-6 \overline{0} \mathrm{dc}$ \\
\hline $92-7$ & 1.00 & 1.20 & 7.68 & 33.3 & 0.23 & -0.69 & 540 & Uncican & $-60 d c$ \\
\hline $92-8$ & 0.00 & 0.00 & 0.00 & 33.3 & 0.00 & -0.74 & 540 & Clean & $-60 \mathrm{dc}$ \\
\hline $92-9$ & 0.80 & 1.00 & 6.40 & 33.3 & 0.19 & -0.79 & 540 & Ewhed & $-100 d c$ \\
\hline $92-10$ & 0.00 & -0.20 & -1.28 & 134.3 & -0.01 & -0.44 & $5400^{-}$ & Ectchal & $-75 \mathrm{dc}$ \\
\hline $92-11$ & 1.00 & 1.20 & 7.68 & 33.3 & 0.23 & -1.01 & 540 & Eiched & $-7 \overline{5} d c$ \\
\hline $92-12$ & 1.30 & 1.10 & 7.04 & 33.3 & 0.21 & 0.84 & 540 & Euched & $-56 \mathrm{dc}$ \\
\hline $92-13$ & 1.10 & 0.80 & 5.12 & 33.3 & 0.15 & 4.62 & 5400 & Eiched & $-60 d c$ \\
\hline $92-14$ & 1.10 & 0.90 & 5.76 & 33.3 & 0.17 & -0.95 & 540 & Clean & $-25 d c$ \\
\hline $92-15$ & 0.00 & 0.20 & 1.28 & 33.3 & 0.04 & $-0.9 i$ & 540 & Cican & Floating $d c$ \\
\hline $92-16$ & 0.80 & 0.70 & 4.48 & 33.3 & 0.13 & $-0.6 \mathrm{i}$ & 540 & Clean & $-25 \mathrm{rf}$ \\
\hline $92-17$ & 0.00 & 0.00 & 0.00 & 158.3 & 0.00 & -1.65 & 540 to 1300 & Golden Color & Floating of \\
\hline $92-18$ & 1.60 & 1.40 & 8.96 & 33.3 & 0.27 & -1.1 & 540 & Micro-droplets & -50 Hoating \\
\hline $92-19$ & 1.50 & 1.30 & 8.32 & 33.3 & 0.25 & -0.67 & 935 & Clean & $-50 \mathrm{rf}$ \\
\hline $92-20$ & 1.00 & 1.00 & 6.40 & 33.58 & 0.19 & -0.22 & 1300 & Clean & $45 \mathrm{rf}$ \\
\hline $92-21$ & 1.00 & 1.20 & 7.68 & 33.58 & 0.23 & -0.39 & 1317 & Cloan & $-40 \pi$ \\
\hline $92-22$ & 1.10 & -3.90 & -24.96 & 23.25 & -1.07 & -0.88 & 1310 & Cloan & $-25 \mathrm{nt}$ \\
\hline $92-23$ & 0.00 & 0.00 & 0.00 & 35.00 & 0.00 & -0.29 & 1267 & Light Golden Color & $-150 \mathrm{di}$ \\
\hline $92-24$ & 0.00 & 0.00 & 0.00 & 35.00 & 0.00 & 59.37 & 1267 & Golden Color & Floating \\
\hline $92-25$ & 1.40 & 2.40 & 15.36 & 25.60 & 0.60 & -0.12 & 1340 & Elched & $-200 d c$ \\
\hline $92-26$ & 0.00 & 0.40 & 2.56 & 25.60 & 0.10 & 50.20 & 1340 & Golden Color & Floating \\
\hline $92-27$ & 0.00 & 1.20 & 7.68 & 25.00 & 0.31 & -0.41 & 970 & Elched & $-400 d c$ \\
\hline $92-28$ & 0.00 & 1.20 & 7.68 & 25.00 & 0.31 & -0.11 & 970 & Smooth Clean & $-400 d c$ \\
\hline $92-29$ & 1.80 & 1.90 & 12.16 & 25.83 & 0.47 & -0.11 & 980 & Cloan & $-110 \pi$ \\
\hline $92-30$ & 0.00 & 0.20 & 1.28 & 26.00 & 0.05 & 13.76 & 980 & Golden Color & Floating \\
\hline $92-31$ & 1.70 & 1.80 & 11.52 & 10.77 & 1.07 & -0.71 & 980 & Clean & $-150 r$ \\
\hline $92-32$ & 0.00 & 0.10 & 0.64 & 10.80 & 0.06 & -0.30 & 980 & Cloan & Floaling \\
\hline $92-33$ & 1.00 & 1.10 & 7.04 & 9.80 & 0.72 & -1.86 & 1300 & Black spols & $-125 \mathrm{nt}$ \\
\hline $92-34$ & 0.00 & 0.10 & 0.64 & 9.80 & 0.06 & 0.67 & 1300 & Golden Color & $-30 \mathrm{rl}$ \\
\hline 92.35 & 1.70 & 1.80 & 11.52 & 12.60 & 0.91 & .121 & 550 & Black spots & $-175 \mathrm{rl}$ \\
\hline $92-36$ & 0.00 & 0.10 & 0.64 & 12.60 & 0.05 & -1.53 & 550 & Golden Color & $-25 \mathrm{rt}$ \\
\hline $92-37$ & 2.00 & 2.20 & 14.08 & 16.10 & 0.87 & 1.68 & 950 & Golden Color & $-100 \pi$ \\
\hline $92-38$ & 2.90 & 2.90 & 18.56 & 16.10 & 1.15 & 1.60 & 950 & Golden Coior & $-100 \mathrm{r}$ \\
\hline $92-39$ & 1.70 & 1.60 & 10.24 & 21.00 & 0.49 & -2.00 & 950 & Black Spots & $-110 \pi$ \\
\hline $92-40$ & 1.80 & 1.50 & 9.60 & 21.00 & 0.46 & -1.61 & 950 & Black Spots & $-110 \mathrm{rl}$ \\
\hline $92-41$ & 2.60 & 2.60 & 16.64 & 10.00 & 1.66 & -1.50 & 910 & Clean & $-165 \pi$ \\
\hline $92-42$ & 1.90 & 2.00 & 12.80 & 4.75 & 2.69 & -1.18 & 930 & Black spots & $-165 \mathrm{rt}$ \\
\hline $92-43$ & 1.60 & 1.60 & 10.24 & 4.75 & 2.16 & 0.63 & 930 & Black spots & $-165 n$ \\
\hline $92-44$ & 1.50 & 1.50 & 9.60 & 7.08 & 1.36 & -1.93 & 930 & Golden spols & $-150 \pi$ \\
\hline$\frac{\mid c-44}{92-45}$ & 1.40 & 1.40 & 8.96 & 7.08 & 1.26 & -1.98 & 930 & Golden spots & $-150 \mathrm{rt}$ \\
\hline
\end{tabular}




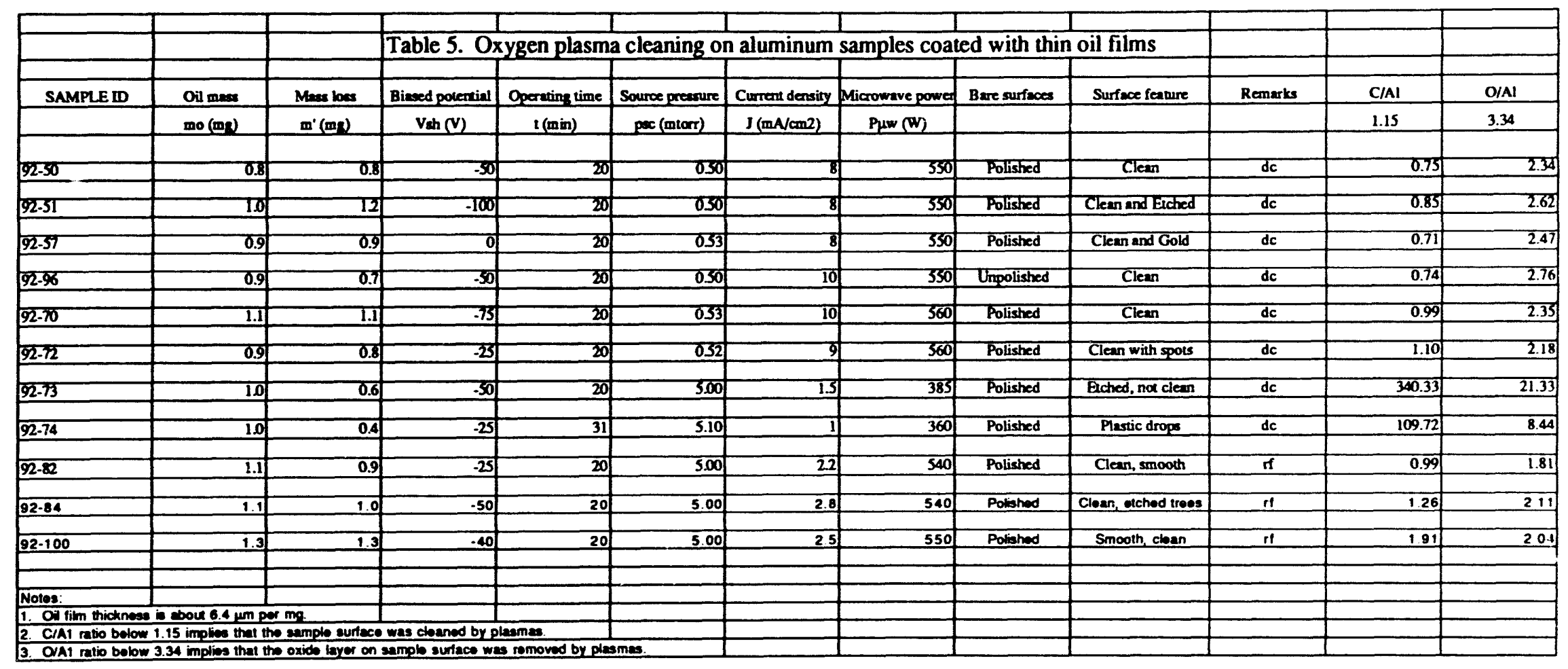




\begin{tabular}{|c|c|c|c|c|c|c|c|c|c|c|c|}
\hline & & & \multicolumn{7}{|c|}{ Table 6. Surface composition of test samples in percentage } & & \\
\hline Samplelelement & Al & $\mathbf{O}$ & C & $\mathbf{M g}$ & $\mathbf{C a}$ & Si & $\mathrm{Cu}$ & $\mathrm{Ag}$ & $\mathbf{P}$ & $\mathrm{Cr}$ & $\mathbf{N}$ \\
\hline 92-50-CON & 18.05 & 58.27 & 18.98 & 0.00 & 0.40 & 0.79 & 0.00 & 0.00 & 3.50 & 0.00 & 0.00 \\
\hline $92-50$ & 23.55 & 55.18 & 17.56 & 3.53 & 0.00 & 0.00 & 0.00 & 0.00 & 0.00 & 0.00 & 0.18 \\
\hline 92-72-CON & 16.23 & 55.35 & 21.61 & 0.00 & 1.17 & 0.68 & 0.00 & 0.00 & 3.11 & 0.00 & 1.84 \\
\hline $92-72$ & 22.72 & 49.57 & 24.97 & 0.91 & 0.29 & 0.67 & 0.00 & 0.00 & 0.00 & 0.00 & 0.87 \\
\hline 92-100-CON & 17.39 & 58.92 & 18.70 & 0.00 & 0.53 & 1.08 & 0.00 & 0.00 & 3.06 & 0.00 & 0.31 \\
\hline $92-100$ & 20.06 & 40.98 & 34.71 & 1.27 & 0.00 & 0.37 & 1.75 & 0.30 & 0.00 & 0.00 & 0.55 \\
\hline Sample mean & 22.11 & 48.58 & 25.75 & 1.90 & 0.10 & 0.35 & 0.58 & 0.10 & 0.00 & 0.00 & 0.53 \\
\hline Control mean & 17.22 & 57.51 & 19.76 & 0.00 & 0.70 & 0.85 & 0.00 & 0.00 & 3.22 & 0.00 & 0.72 \\
\hline Bulk alloy & 97.90 & 0.00 & 0.00 & 1.00 & 0.00 & 0.60 & 0.28 & 0.00 & 0.00 & 0.25 & 0.00 \\
\hline
\end{tabular}




\section{ECR PLASMATRON}

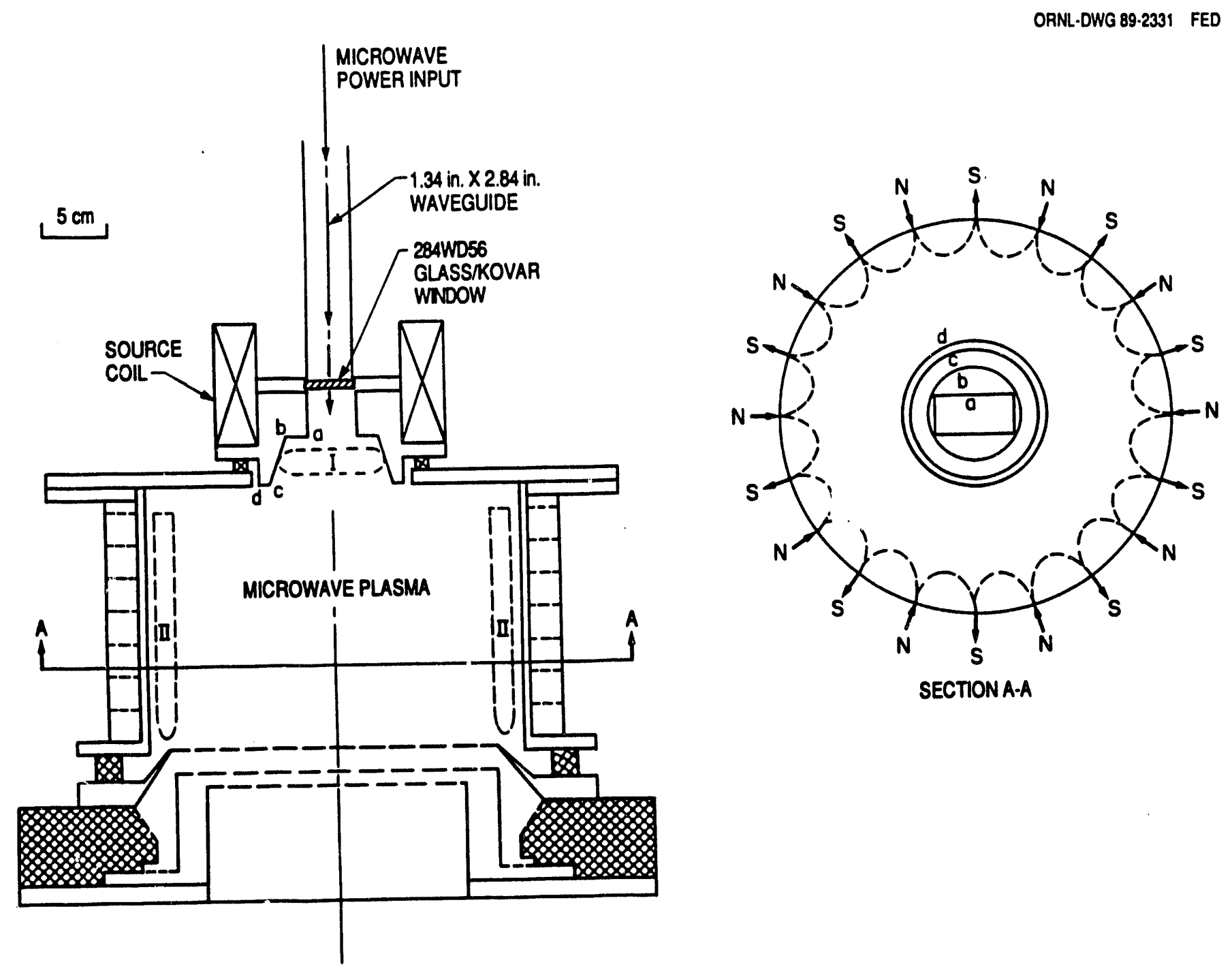

Fig. 1. Schematic of microwave ECR multicusp ion source. 


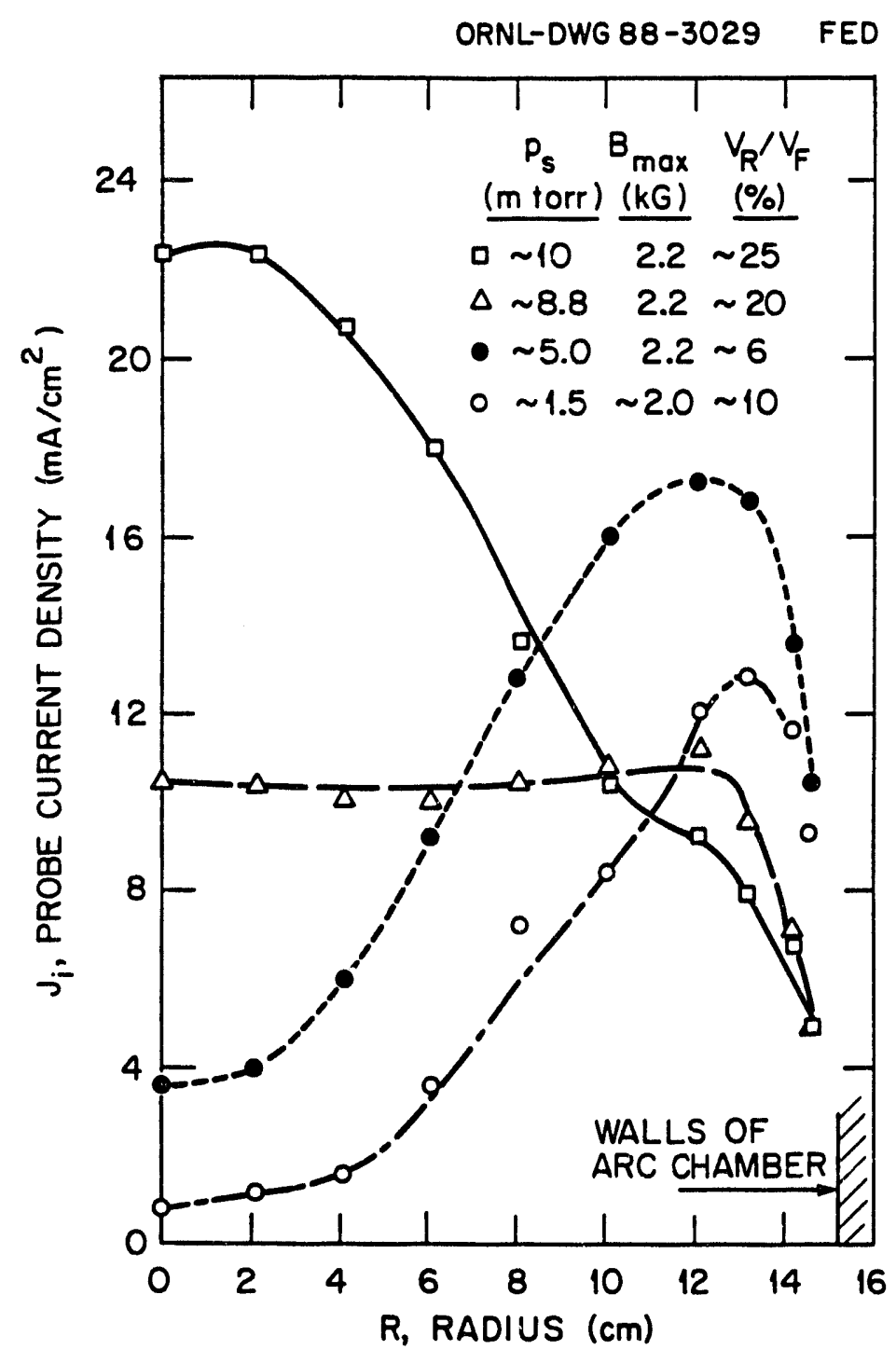

Fig. 2. Effect of source pressure, $\mathrm{p}_{\mathrm{s}}$, on hydrogen plasma produced by source shown in Fig. 1. 


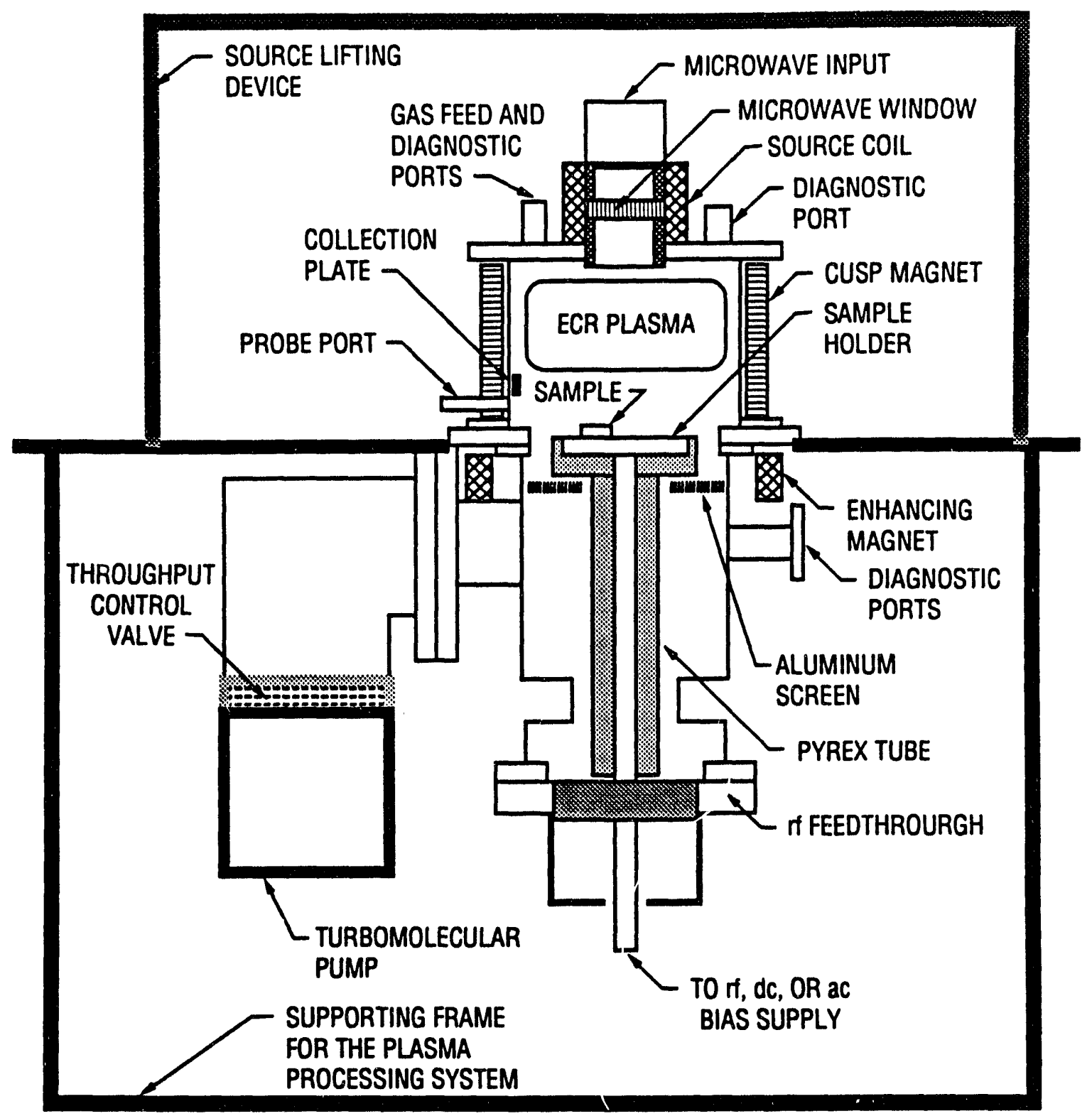

Fig. 3. Test stand including plasma source, sample holder, vacuum chamber, and vacuum system, which is set up for plasma cleaning experiments. 


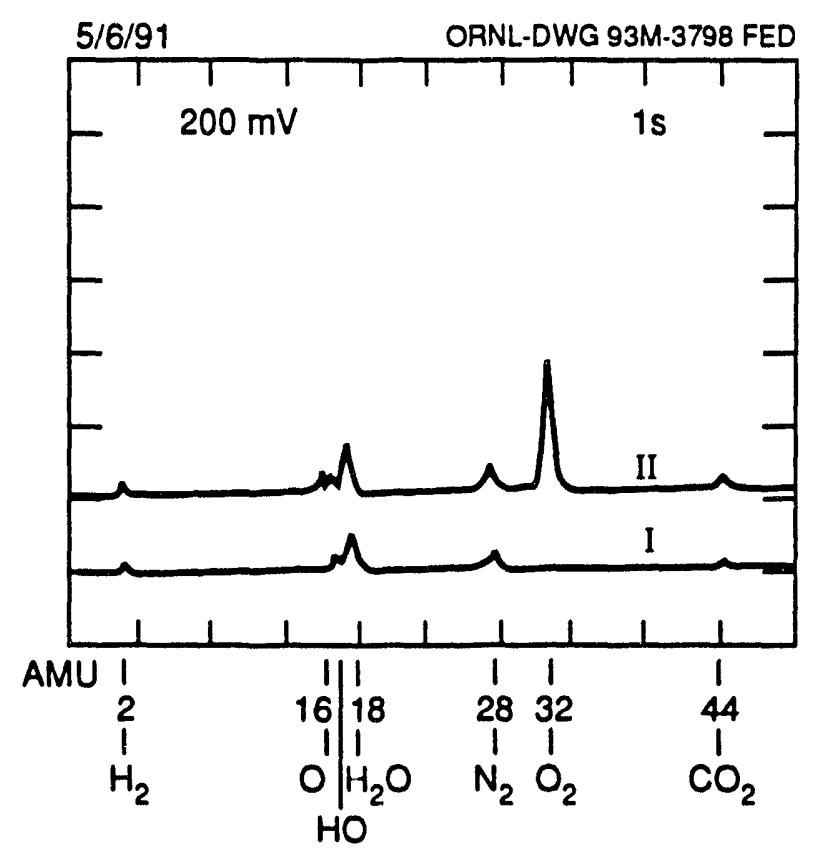

Fig. 4. Mass spectra of RGA: (I) for typical background case and (II) for case with pure oxygen feed. 


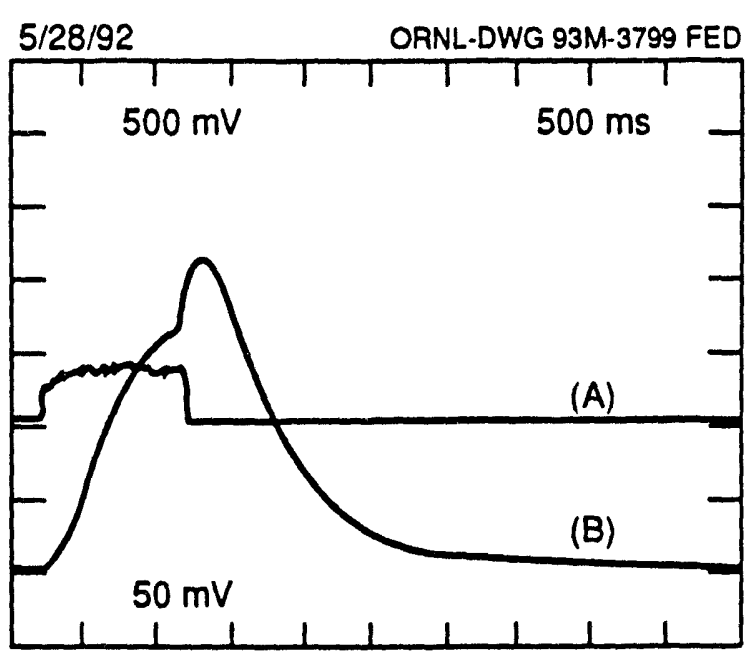

Fig. 5. Typical waveforms (a) of probe current and $(b)$ of mass peak of $\mathrm{CO}$ for pulsed discharge. 


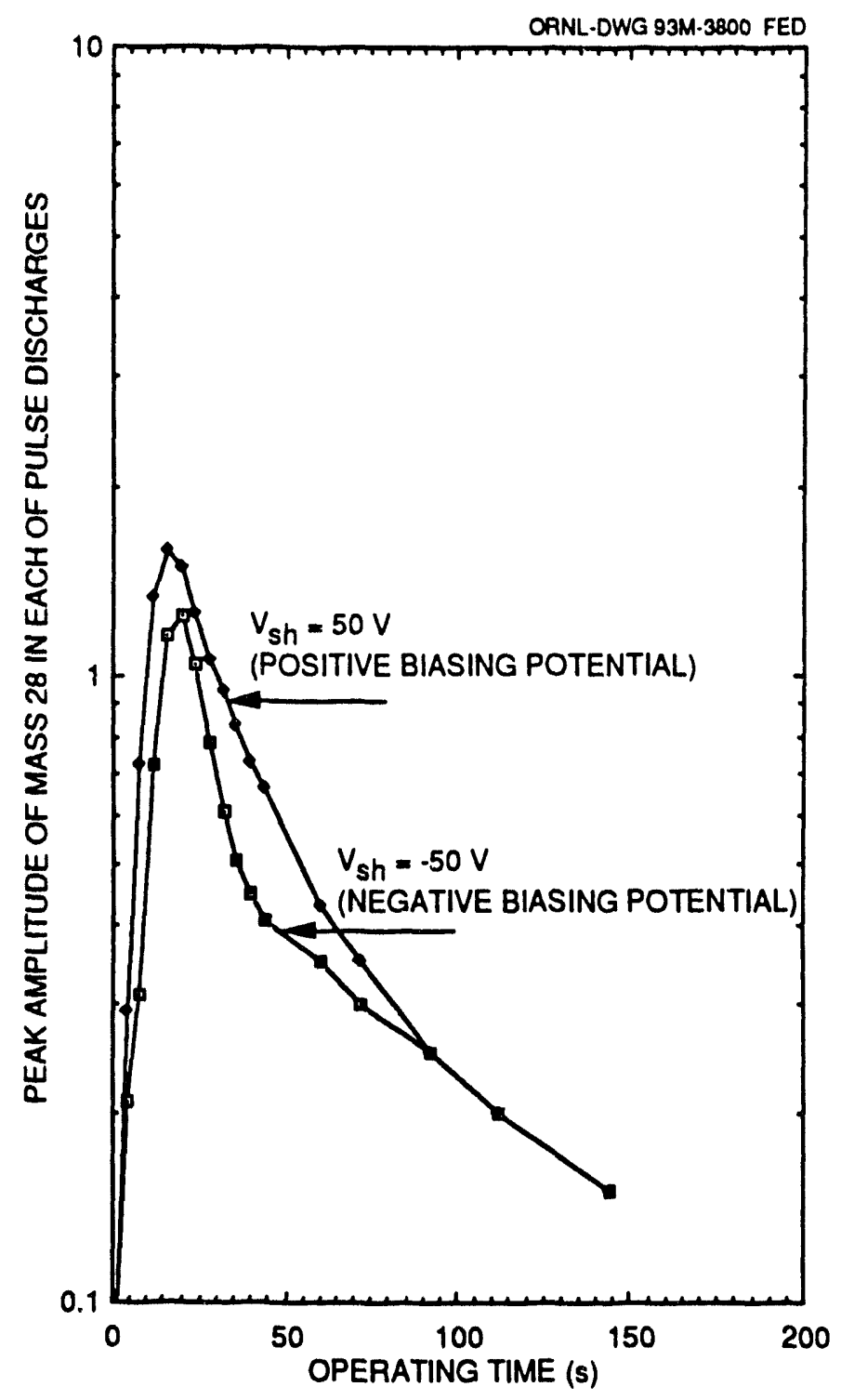

Fig. 6 Signal changes of mass peak of CO (28 amu) during oxygen plasma cleaning without test samples. 

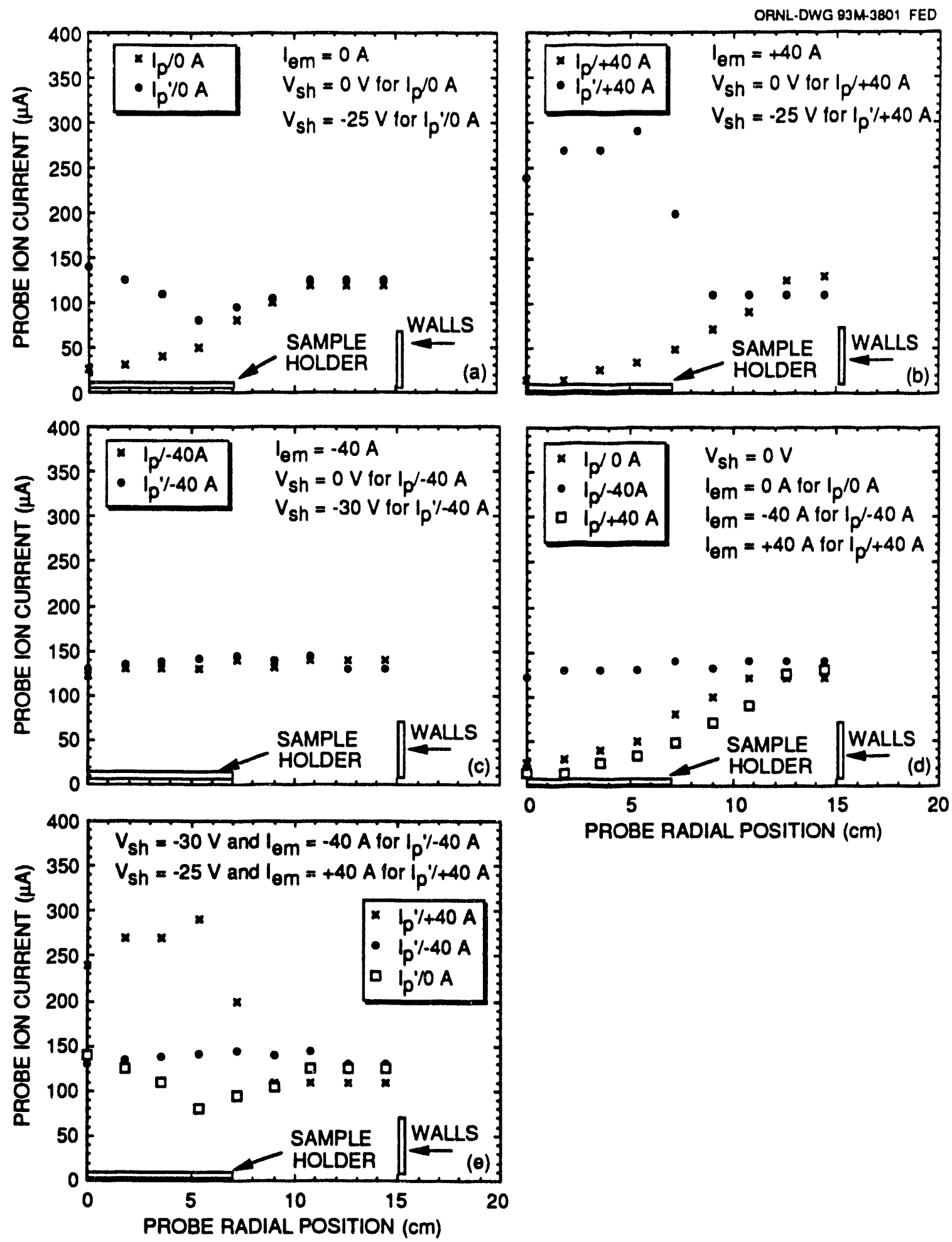

Fig. 7. Plasma radial profiles in transverse plane at downstream end of plasma chamber measured for low-pressure oxygen discharges with different discharge parameters: potentials $\left(\mathrm{V}_{\mathrm{sh}}\right)$ of the floated sample holder and enhanced magnet currents $\left(\mathrm{Iem}_{\mathrm{em}}\right)$.

(a) $\mathrm{I}_{\mathrm{em}}=0 \mathrm{~A}, \mathrm{~V}_{\mathrm{sh}}=0 \mathrm{~V}$ or $-25 \mathrm{~V}$; (b) $\mathrm{I}_{\mathrm{em}}=+40 \mathrm{~A}, \mathrm{~V}_{\mathrm{sh}}=0 \mathrm{~V}$, or $-25 \mathrm{~V}$;

(c) $\mathrm{I}_{\mathrm{em}}=-40 \mathrm{~A}, \mathrm{~V}_{\mathrm{sh}}=0 \mathrm{~V}$ or $-30 \mathrm{~V} ;(d) \mathrm{V}_{\mathrm{sh}}=0 \mathrm{~V}, \mathrm{I}_{\mathrm{em}}=-40 \mathrm{~A}, 0 \mathrm{~A}$, or $+40 \mathrm{~A} ;(e)$ $\mathrm{V}_{\mathrm{sh}}=-25$ to $-30 \mathrm{~V}, \mathrm{I}_{\mathrm{em}}=-40 \mathrm{~A}, 0 \mathrm{~A}$, or $+40 \mathrm{~A}$ 

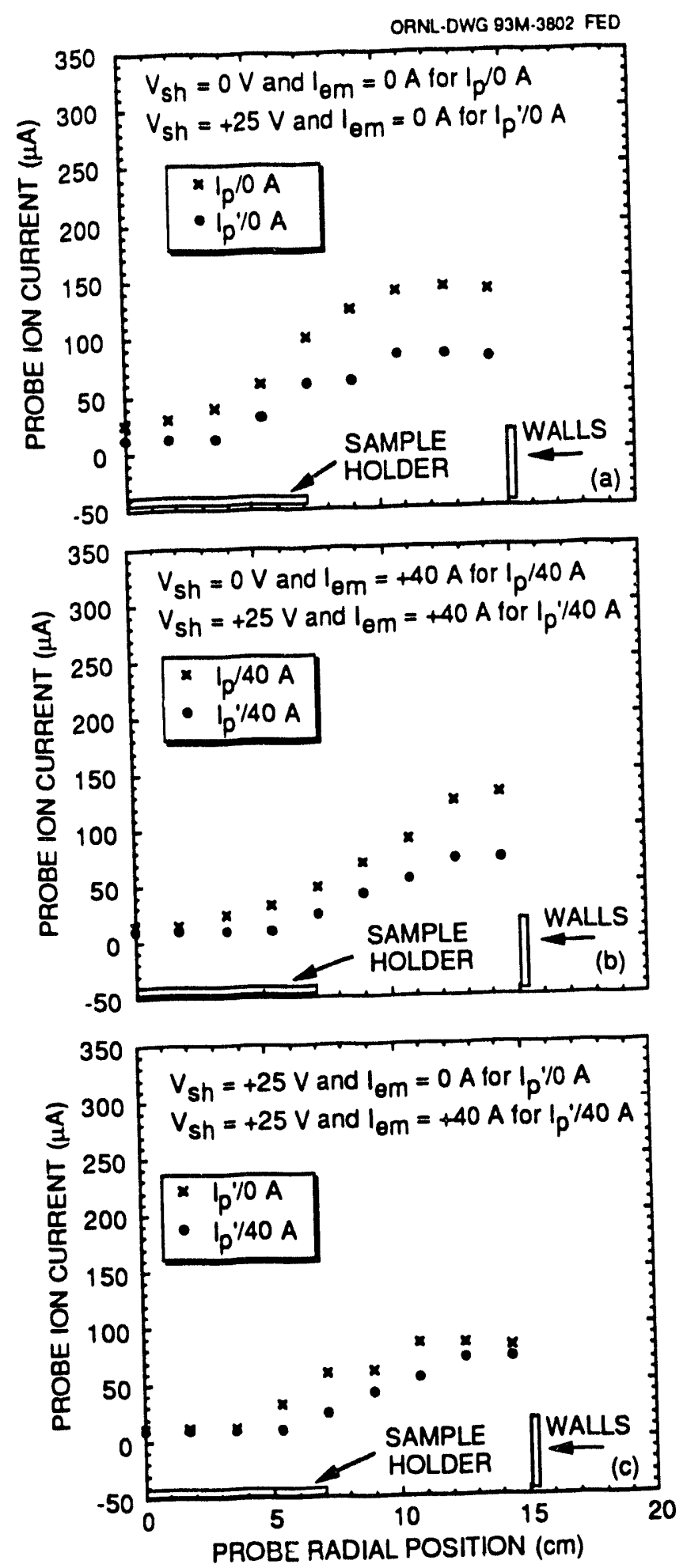

Fig. 8. Plasma profiles for low-pressure oxygen discharges with sample holder grounded $\left(\mathrm{V}_{\mathrm{sh}}=0 \mathrm{~V}\right)$ or positively biased $\left(\mathrm{V}_{\mathrm{sh}}=+25 \mathrm{~V}\right)$ and different, enhanced magnet currents $\left(\mathrm{I}_{\mathrm{em}}\right)$.

(a) $\mathrm{I}_{\mathrm{em}}=0 \mathrm{~A}, \mathrm{~V}_{\mathrm{sh}}=0 \mathrm{~V}$ or $+25 \mathrm{~V} ;\left(\right.$ b) $\mathrm{I}_{\mathrm{em}}=+40 \mathrm{~A}, \mathrm{~V}_{\mathrm{sh}}=0 \mathrm{~V}$ or $+25 \mathrm{~V}$;

(c) $\mathrm{V}_{\mathrm{sh}}=+25 \mathrm{~V}, \mathrm{I}_{\mathrm{em}}=0 \mathrm{~A}$ or $+40 \mathrm{~A}$ 

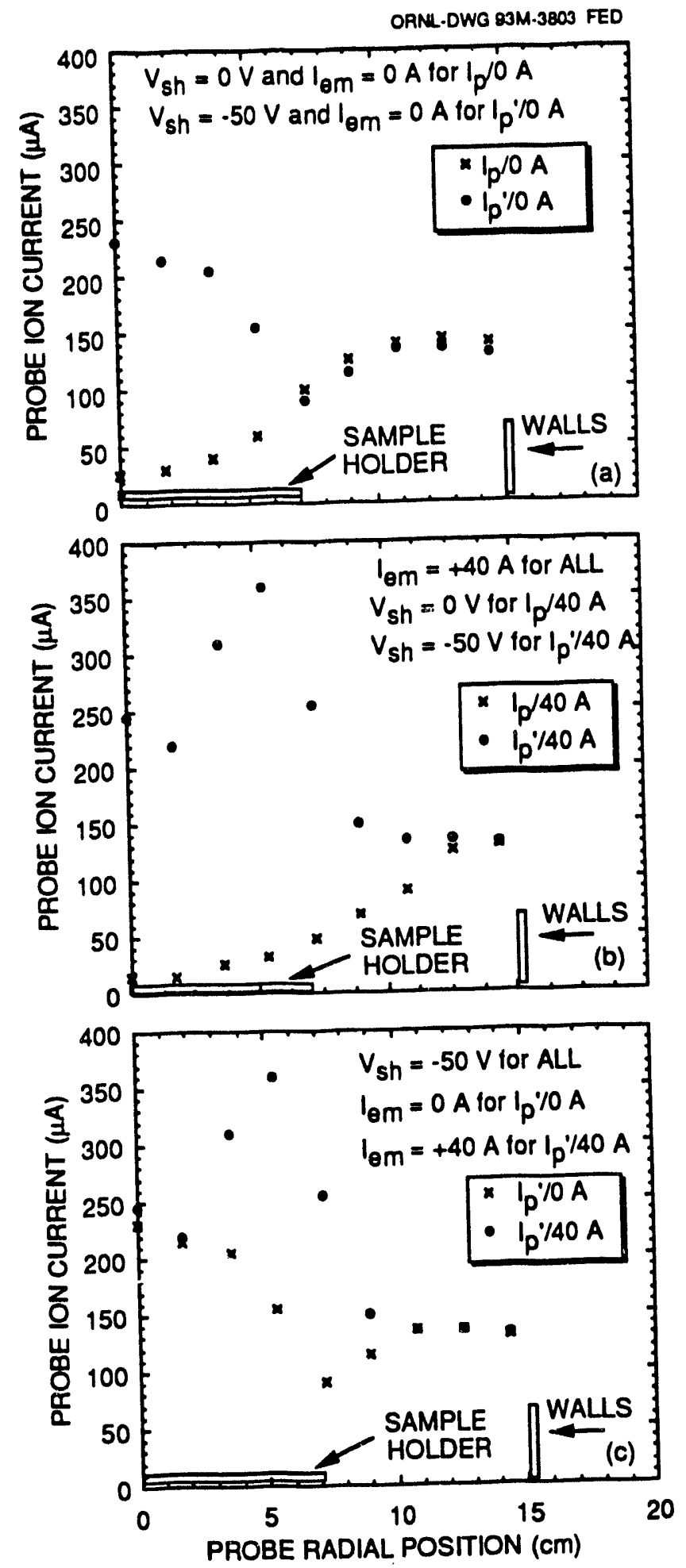

Fig. 9. Plasma profiles for low-pressure oxygen discharges with sample holder grounded $\left(\mathrm{V}_{\mathrm{sh}}=0 \mathrm{~V}\right)$ or negatively biased $\left(\mathrm{V}_{\mathrm{sh}}=-50 \mathrm{~V}\right)$, and different enhanced magnet currents $\left(\mathrm{I}_{\mathrm{em}}\right)$.

(a) $\mathrm{I}_{\mathrm{em}}=0 \mathrm{~A}, \mathrm{~V}_{\mathrm{sh}}=0 \mathrm{~V}$ 0r $-50 \mathrm{~V}$; (b) $\mathrm{I}_{\mathrm{em}}=+40 \mathrm{~A}, \mathrm{~V}_{\mathrm{sh}}=0 \mathrm{~V}$ or $-50 \mathrm{~V}$;

(c) $\mathrm{V}_{\mathrm{sh}}=-50 \mathrm{~V}, \mathrm{I}_{\mathrm{em}}=0 \mathrm{~A}$ or $+50 \mathrm{~A}$ 
OANL.DWG 93M-3804 FED
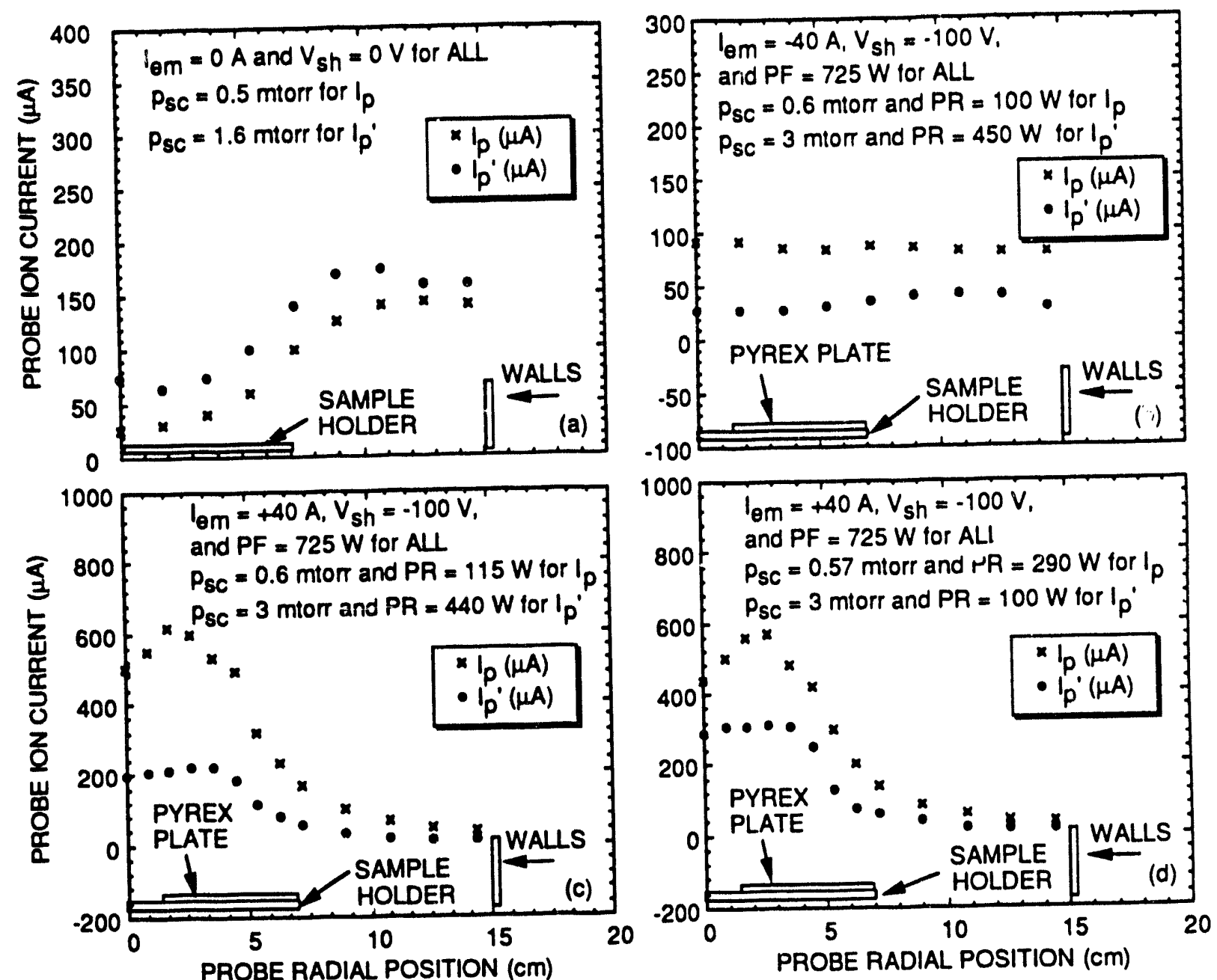

Fig. 10. Effect of source pressure $\left(p_{s c}=-0.6-\right.$ mtorr or $\left.\sim 3-\mathrm{mtorr}\right)$ on plasma density and profiles.

(a:) $\mathrm{I}_{\mathrm{em}}=0 \mathrm{~A}$ and $\mathrm{V}_{\mathrm{sh}}=0 \mathrm{~V} ;(b) \mathrm{I}_{\mathrm{em}}=-40 \mathrm{~A}$ and $\mathrm{V}_{\mathrm{sh}}=-100 \mathrm{~V} ;(c) \mathrm{I}_{\mathrm{em}}=+40 \mathrm{~A}$ and $V_{\mathrm{sh}}=-100 \mathrm{~V} ;(d) I_{\mathrm{em}}=+40 \mathrm{~A}$ and $\mathrm{V}_{\mathrm{sh}}=-100 \mathrm{~V}$ 

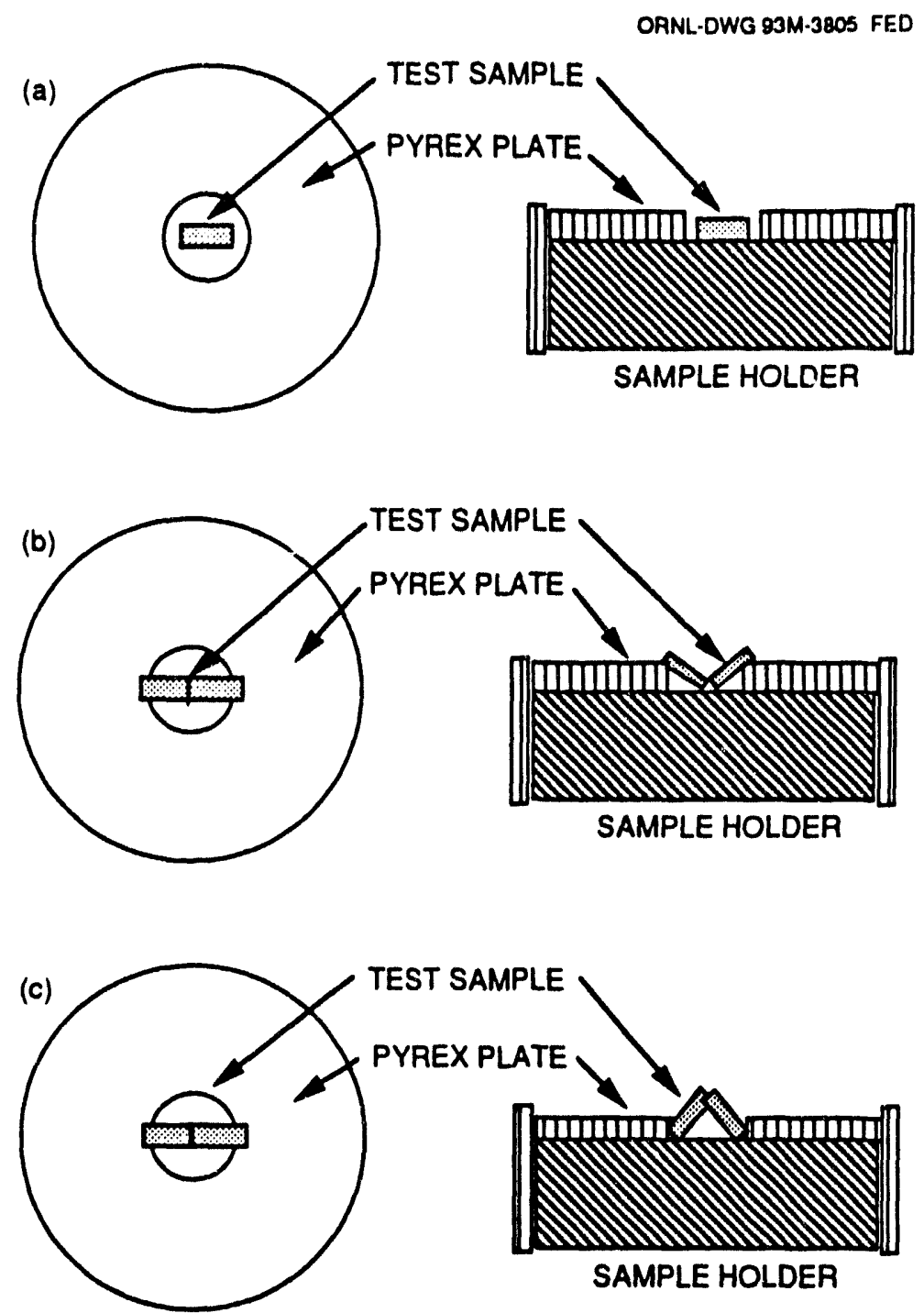

Fig. 11. Arrangements for placing test samples on the sample holder.

(a:) Sample with flat surface; (b) Samples for simulating concave surfaces;

(c) Samples for simulating convex surfaces 


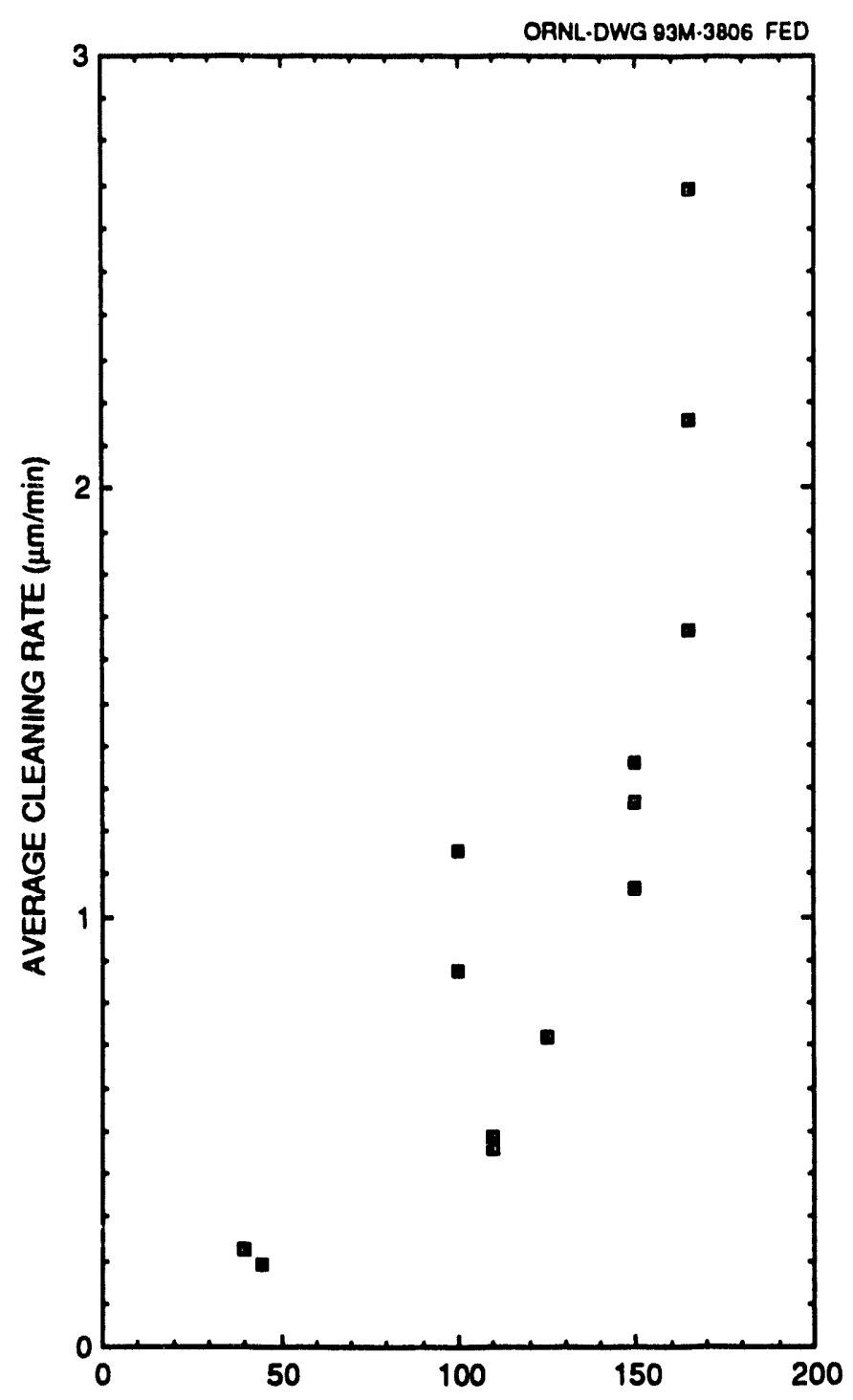

NEGATIVE i BIASED POTENTIAL TO TEST SAMPLES (V)

Fig. 12. Change of average cleaning rate as functions of $\mathrm{rf}$ biased potential sample holder. 


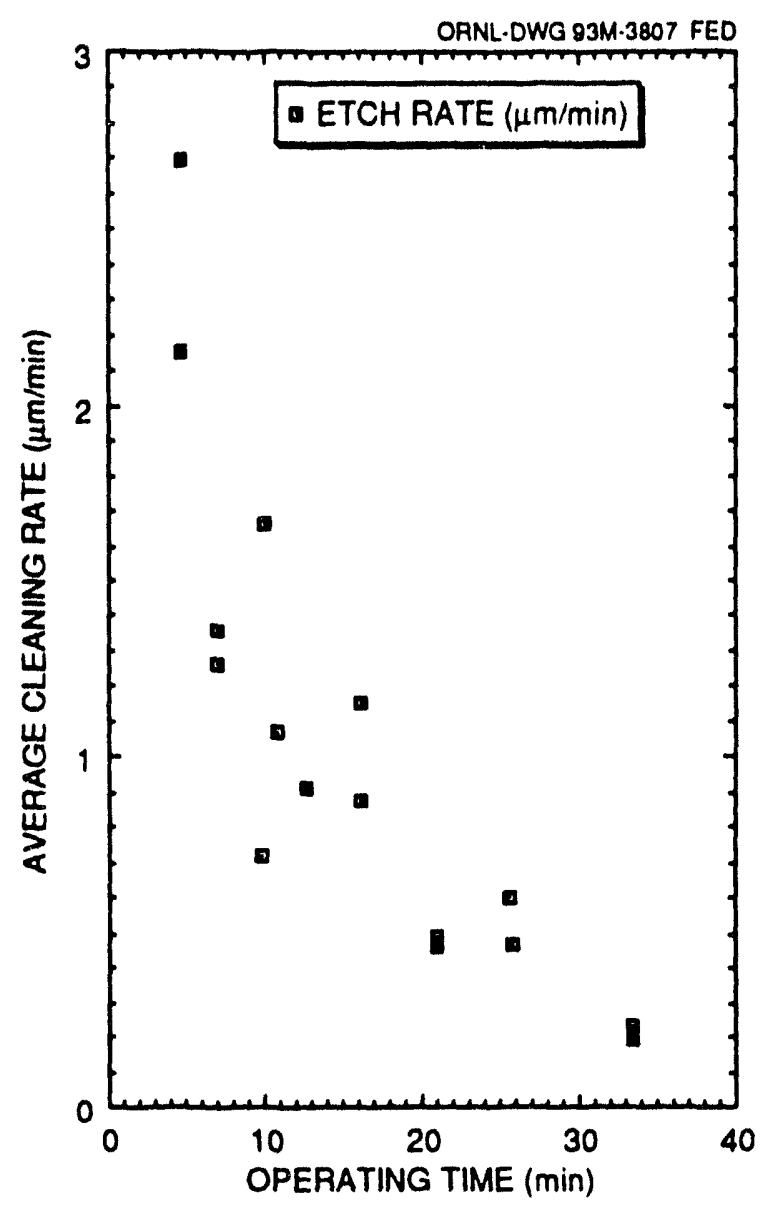

Fig. 13. Change of average cleaning rate as function of operating time of plasma cleaning. 


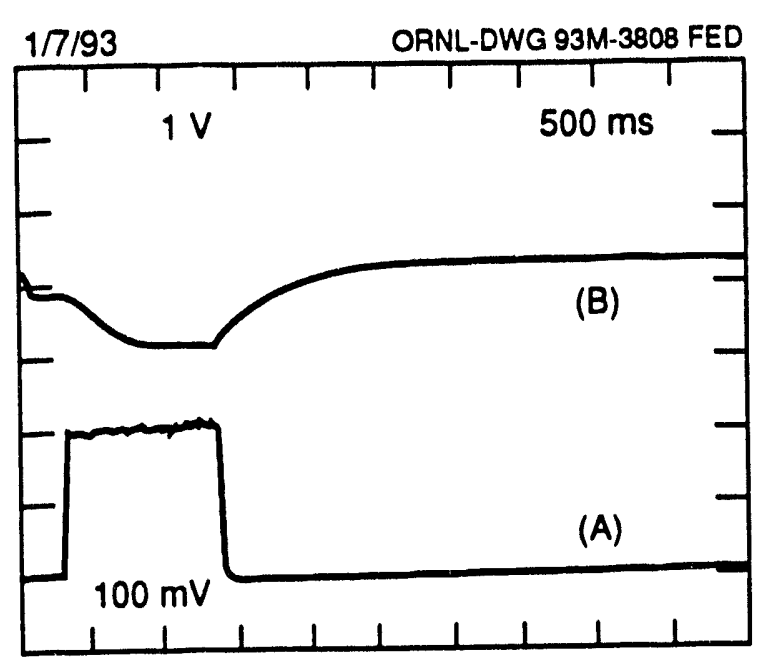

Fig. 14. Typical waveforms (A) of probe current and (B) of mass peak of oxygen molecule, $\mathrm{O}_{2}$, for pulsed discharge. 


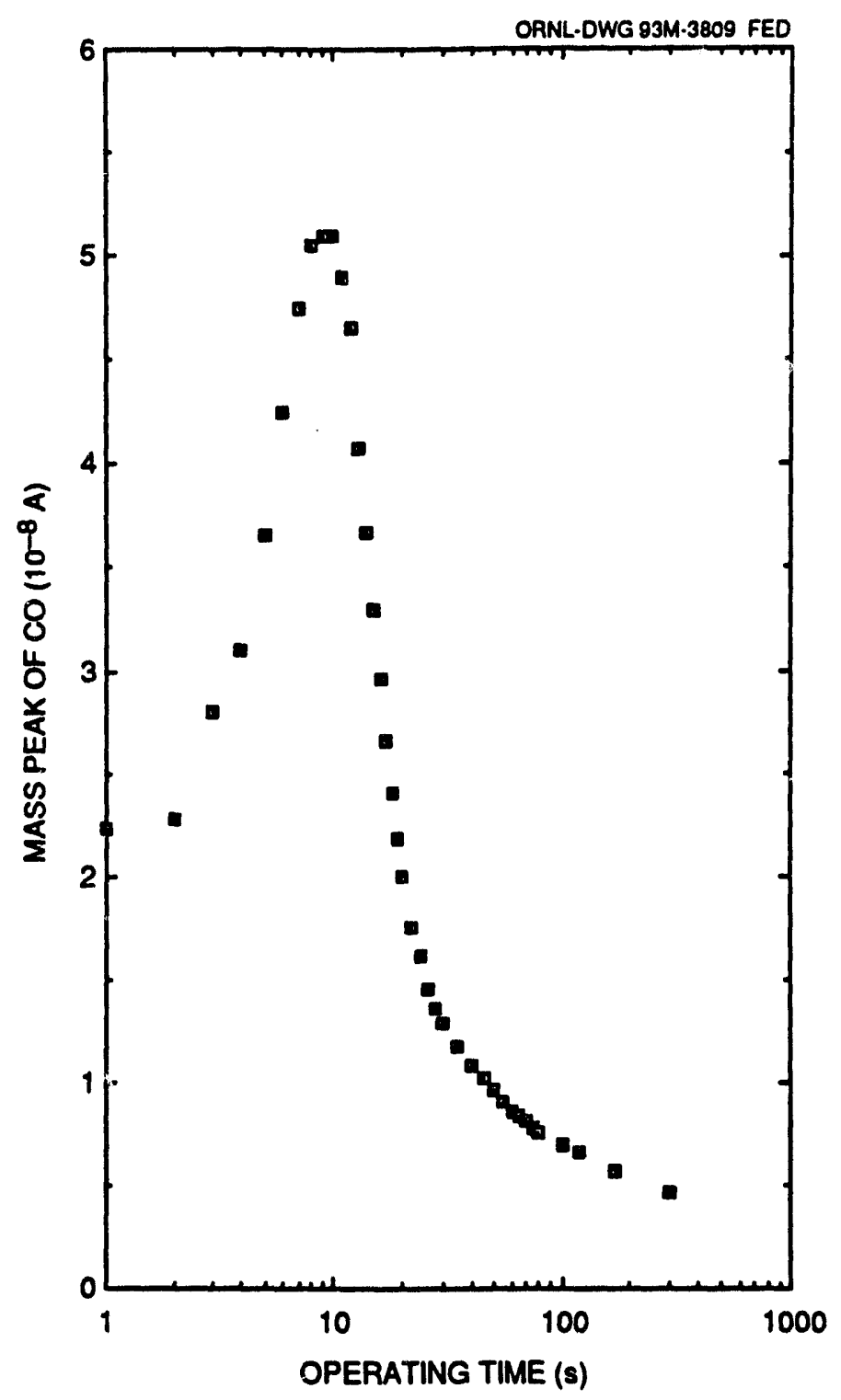

Fig. 15. Signal changes of mass peak of $\mathrm{CO}(28 \mathrm{amu})$ during oxygen plasma cleaning with test sample. 


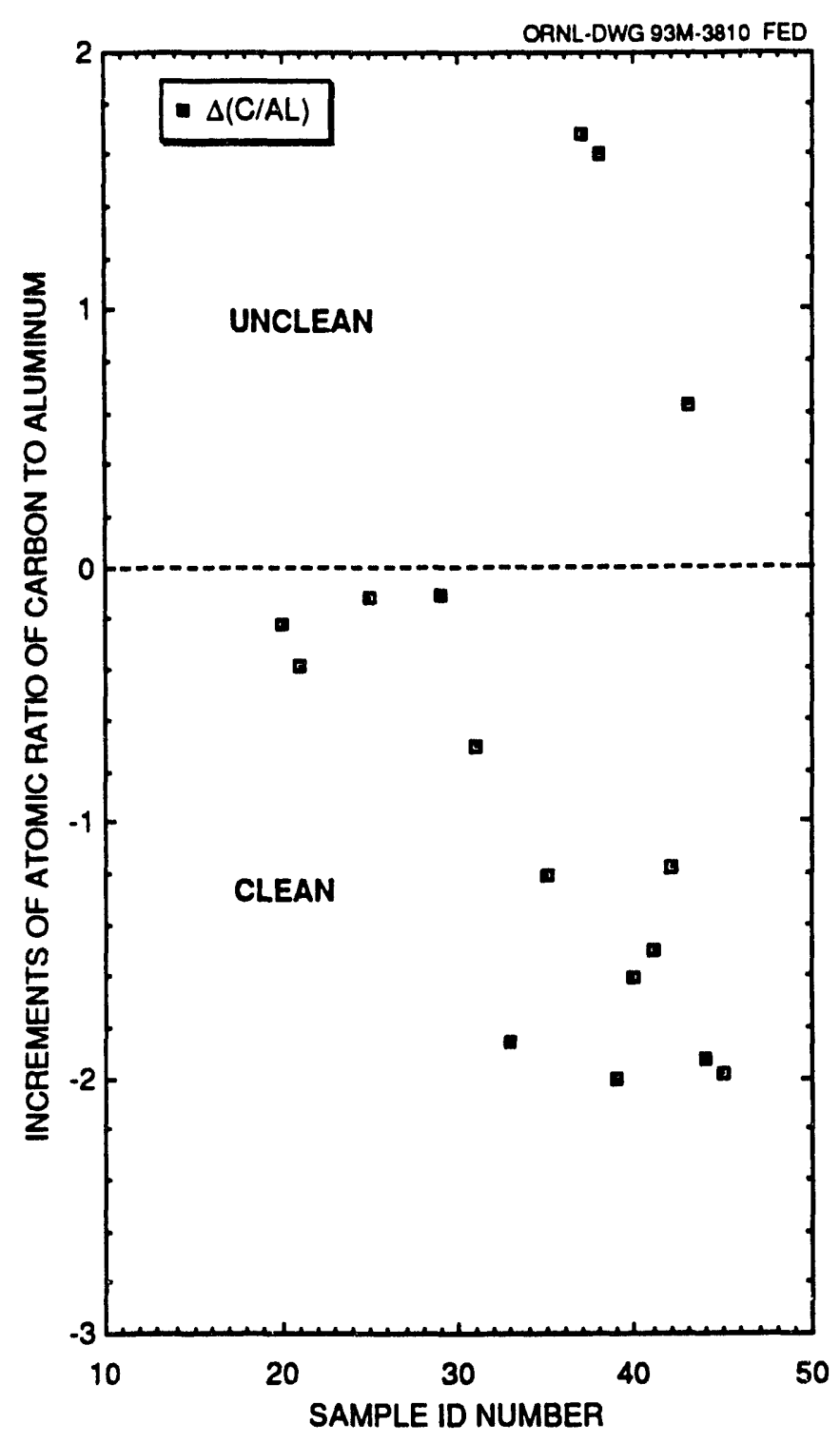

Fig. 16. Cleanliness of samples evaluated by value of $\Delta(\mathrm{C} / \mathrm{Al})$ : Positive values mean unclean sample surfaces, and negative values mean clean sample surfaces. 
ORNL/TM-12495

Dist. Category UC-420a,d,f

\section{INTERNAL DISTRIBUTION}
1. M. A. Akerman
2. W. D. Babb
3. C. C. Baker
4. G. C. Barber
5. D. E. Bartine
6. L. A. Berry
7. V. B. Campbell
8. B. A. Carreras
9. J. B. O. Caughman
10. R. Churnetski
11. C. M. Cook
12. R. A. Dory
13. A. L. Glover
14. J. M. Googin
15. J. T. Greer
16. H. H. Haselton
17. D. J. Hoffman
18. S. L. Milora

19. W. D. Nelson

20. D. E. Schechter

21. R. M. Schilling

22. T. E. Shannon

23. J. Sheffield

24. J. E. Simpkins

25. W. L. Stirling

26-27. L. M. Thompson

28-36. C. C. Tsai

37. J. H. Whealton

38. Central Research Library

39. Document Reference Section

40. Fusion Energy Division Library

41. Engineering Technology/Fusion Energy Publications Office

42. ORNL Patent Section

43-44. Laboratory Records Department

45. Laboratory Records, RC

\section{EXTERNAL DISTRIBUTION}

46. T. Eastman, Program Director, Magnetospheric Physics, Division of Atmospheric Sciences, National Science Foundation, 1800 G Street, Washington, DC 20550

47. J. D. Callen, Department of Nuclear Engineering, University of Wisconsin, Madison, WI 53706-1687

48. Director, Office of Fusion Energy, Office of Energy Research, ER-50 Germantown, U.S. Department of Energy, Washington, DC 20545

49. R. W. Conn, Engineering IV, 405 Hilgard Avenue, University of California, Los Angeles, CA 90024-1597

50. S. O. Dean, Fusion Power Associates, Inc., 2 Professional Drive, Suite 248, Gaithersburg, MD 20879

51. H. K. Forsen, Bechtel Group, Inc., Research Engineering, P.O. Box 3965, San Francisco, CA 94119

52. J. R. Gilleland, L-644, Lawrence Livermore National Laboratory, P.O. Box 5511, Livermore, CA 94550

53. R. W. Gould, Department of Applied Physics, California Institute of Technology, Pasadena, CA 91125

54. R. A. Gross, Plasma Research Laboratory, Columbia University, New York, NY 10027

55. D. M. Meade, Princeton Plasma Physics Laboratory, P.O. Box 451, Princeton, NJ 08543 
56. M. Roberts, International Programs, Office of Fusion Energy, Office of Energy Research, ER-52 Germantown, U.S. Department of Energy, Washington, DC 20545

57. W. M. Stacey, Fusion Research Center and Nuclear Engineering Program ESM Building 0225, Georgia Institute of Technology, Atlanta, GA 30332

58. D. Steiner, Nuclear Engineering Department, NES Building, Tibbetts Avenue, Rensselaer Polytechnic Institute, Troy, NY 12181

59. R. Varma, Physical Research Laboratory, Navrangpura, Ahmedabad 380009, India

60. Bibliothek, Max-Planck Institut für Plasmaphysik, Boltzmannstrasse 2, D-8046 Garching, Federal Republic of Germany

61. Bibliothek, Institut für Plasmaphysik, KFA Jülich GmbH, Postfach 1913, D-5170 Jülich, Federal Republic of Germany

62. Bibliothek, KfK Karlsruhe GmbH, Postfach 3640, D-7500 Karlsruhe 1, Federal Republic of Germany

63. Bibliotheque, Centre de Récherches en Physique des Plasmas, Ecole Polytechnique Fédérale de Lausanne, 21 Avenue des Bains, $\mathrm{CH}-1007$ Lausanne, Switzerland

64. F. Prevot, CEN/Cadarache, Departement de Recherches sur la Fusion Côntrolée, F-13108 Saint-Paul-lez-Durance Cedex, France

65. Bibliothèque, CEN/Cadarache, F-13108 Saint-Paul-lez-Durance Cedex, France

66. Library, Culham Laboratory, UKAEA, Abingdon, Oxfordshire, OX14 3DB, England

67. Library, JET Joint Undertaking, Abingdon, Oxfordshire OX14 3EA, England

68. Library, FOM-Instituut voor Plasmafysica, Rijnhuizen, Edisonbaan 14, 3439 MN Nieuwegein, The Netherlands

69. Library, Institute of Plasma Physics, Nagoya University, Chikusa-ku, Nagoya 464, Japan

70. Library, International Centre for Theoretical Physics, P.O. Box 586, I-34100 Trieste, Italy

71. Library, Centro Richerche Energia Frascati, C.P. 65, I-00044 Frascati (Roma), Italy

72. Library, Plasma Physics Laboratory, Kyoto University, Gokasho, Uji, Kyoto 611, Japan

73. Plasma Research Laboratory, Australian National University, P.O. Box 4, Canberra, A.C.T. 2601, Australia

74. Library, Japan Atomic Energy Research Institute, Naka Fusion Research Establishment, 801-1 Mukoyama, Naka-machi, Naka-gun, Ibaraki-ken, Japan

75. Library, Japan Atomic Energy Research Institute, Tokai, Ibaraki-ken 319-11, Japan

76. T. V. George, Plasma Technologies Branch, Division of Development and Technology, Office of Fusion Energy, Office of Energy Research, ER-531 Germantown, U.S. Department of Energy, Washington, DC 20545

77. E. Oktay, Division of Confinement Systems, Office of Fusion Energy, Office of Energy Research, ER-55 Germantown, U.S. Department of Energy, Washington, DC 20545

78. H. S. Staten, Plasma Technologies Branch, Division of Development and Technology, Office of Fusion Energy, Office of Energy Research, ER-531 Germantown, U.S. Department of Energy, Washington, DC 20545

79. R. L. Abbott, U.S. Army, SCD, DASD-H-D, P.O. Box 1500, Huntsville, AL 35807

80. P. Caruso, U.S. Army, SDC, DASD-H-D, P.O. Box 1500, Huntsville, AL 35807 
81. R. J. Dowling, Division of Development and Technology, Office of Fusion Energy, Office of Energy Research, ER-531 Germantown, U.S. Department of Energy, Washington, DC 20545

82. L. R. Grisham, Princeton Plasma Physics Laboratory, P.O. Box 451, Princeton, NJ 08544

83. J. Kim, Rm. 34/27, GA Technologies, Inc., P.O. Box 85608, San Diego, CA 92138

84. M. D. Smith, Dept. 837, XD43, Allied-Signal Aerospace Company, Kansas City Division, P.O. Box 419159, Kansas City, Missouri 64141-6159

85. Jay Stimmel, MS C920, Los Alamos National Laboratory, P.O. Box 1663, Los Alamos, New Mexico 87545

86. Cynthia Sandoval, Los Alamos National Laboratory, P.O. Box 1663, Los Alamos, New Mexico 87545

87. Joe Martz, Los Alamos National Laboratory, P.O. Box 1663, Los Alamos, New Mexico 87545

88. Skip Christy, Martin Marietta Specialty Components, Inc., P.O. Box 2908, Largo, Florida 34649-2908

89. Robyn Stiefeld, Fiv. 6611, Sandia National Laboratories, P.O. Box 5800, Albuquerque, New Mexico 87185

90. Pamela P. Ward, Sandia National Laboratories, P.O. Box 5800, Albuquerque, New Mexico 87185

91. Office of the Assistant Manager for Energy Research and Development, U.S. Department of Energy, ORO, P.O. Box 2000, Oak Ridge, TN 37831

92-132. Given distribution as shown in DOE/OSTI-4500-R75, Magnetic Fusion Energy (Category UC-20 a,d,f: Plasma Fusion Systems, Fusion Systems, Experimental Plasma Physics) 


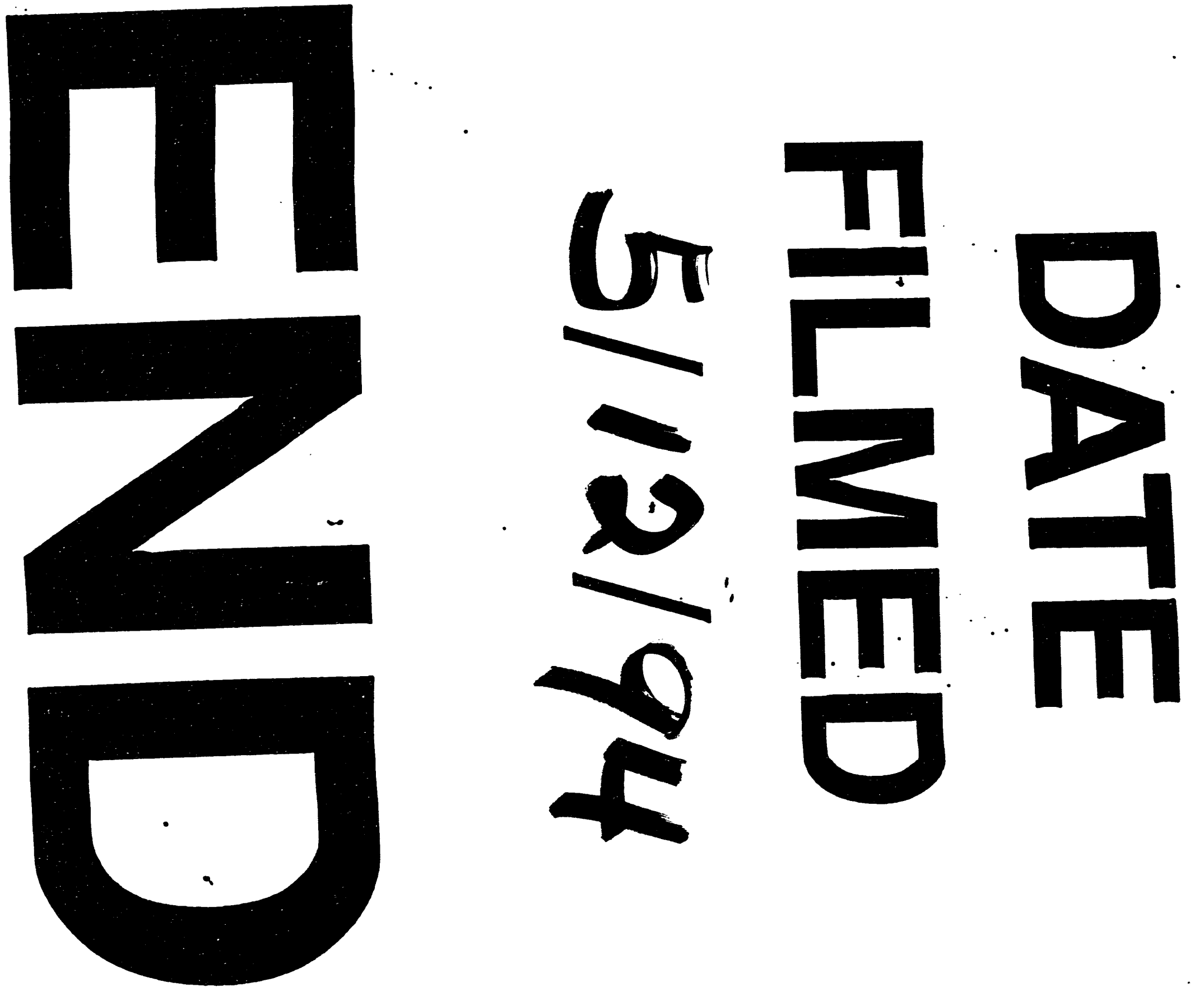




$$
\text { س. }
$$

